\title{
A REGULAMENTAÇÃO DE SERVIÇOS E A COERÊNCIA REGULATÓRIA: UMA LEITURA DOS MEGA-ACORDOS A PARTIR DA PERSPECTIVA BRASILEIRA
}

\author{
Dissertação de Mestrado \\ Orientador: Professor Titular Dr. Umberto Celli Junior
}

UNIVERSIDADE DE SÃO PAULO

FACULDADE DE DIREITO

São Paulo - SP

2018 



\title{
A REGULAMENTAÇÃO DE SERVIÇOS E A COERÊNCIA REGULATÓRIA: UMA LEITURA DOS MEGA-ACORDOS A PARTIR DA PERSPECTIVA BRASILEIRA
}

\begin{abstract}
Dissertação de Mestrado apresentada à Banca Examinadora do Programa de Pós-Graduação em Direito, da Faculdade de Direito da Universidade de São Paulo, na área de concentração Comércio Internacional, sob a orientação do Prof. Titular Dr. Umberto Celli Junior
\end{abstract}

UNIVERSIDADE DE SÃO PAULO

FACULDADE DE DIREITO

São Paulo - SP

2018 
Ficha catalográfica

Azevedo, Milena da Fonseca

A Regulamentação de Serviços e a Coerência Regulatória: Uma Leitura Dos Mega-Acordos A Partir Da Perspectiva Brasileira / Milena da Fonseca Azevedo; orientador Umberto Celli Junior -São Paulo, 2018. 256

Dissertação (Mestrado - Programa de Pós-Graduação em Direito Internacional) - Faculdade de Direito, Universidade de São Paulo, 2018.

1. Regulação de serviços. 2. Coerência regulatória. 3. Mega-acordos. 4. Direito do comércio internacional. 5. Brasil. I. Celli Junior, Umberto, orient. II. Título. 


\section{FOLHA DE AVALIAÇÃO}

Nome: AZEVEDO, Milena da Fonseca

Título: A Regulamentação de Serviços e a Coerência Regulatória: Uma Leitura dos Megaacordos A Partir Da Perspectiva Brasileira

Dissertação apresentada à Faculdade de Direito da Universidade de São Paulo para obtenção do título de Mestre em Direito.

Aprovado em:

Banca Examinadora

Prof. Dr.

Instituição:

Julgamento:

Profa. Dra.

Instituição:

Julgamento:

Prof.Dr.

Instituição:

Julgamento: 

A Deus, por me sustentar todos os dias.

Aos meus pais, Vera e Lourival, pelo apoio, amor, confiança e por me ensinarem tudo que sei.

À minha irmã, Mariana, por ser minha melhor amiga e maior companheira. 



\section{RESUMO}

Milena da Fonseca Azevedo. A Regulamentação de Serviços e a Coerência Regulatória: Uma Leitura Dos Mega-Acordos A Partir Da Perspectiva Brasileira. 2018. 256 p. Dissertação de Mestrado - Faculdade de Direito, Universidade de São Paulo, São Paulo, 2018 .

A coerência regulatória tem emergido como um tema constante nos acordos de comércio e negociações. Isso porque, com a desgravação das tarifas a níveis baixíssimos, as barreiras regulatórias passaram a ser o grande foco das negociações. Ocorre que esse tema ainda está bastante voltado para o comércio de bens, enquanto o de serviços é um tema que ainda necessita de avanços regulatórios. Em levantamento aos acordos assinados pelo Brasil, notou-se que umas das obrigações do bloco do Mercosul é a busca por harmonização. Esta foi incorporada em diversos acordos de complementação econômica assinados após a formação do bloco com outros países da região. Mais recentemente, o Brasil assinou um acordo com Peru em comércio de serviços, investimento e compras governamentais. Tal acordo, conforme noticiado, foi inspirado no acordo TPP. Nas disposições de serviços, há obrigações GATS-plus, dentre outras, em regulação doméstica e reconhecimento. O TPP foi o primeiro mega-acordo assinado e feito público até o momento. Apesar de não estar em vigor, o TPP acabou por trazer ao comércio internacional um parâmetro regulatório às negociações que estão em andamento, incluindo o próprio tema da coerência regulatória e levando a regulação de serviços a outro patamar. Em paralelo, outro mega-acordo sendo negociado é aquele entre EUA e UE, o TTIP. Esse acordo de comércio e investimento, se vier a entrar em vigor - no momento, as negociações estão paralisadas - deverá conter disposições de cooperação e boas práticas regulatórias em serviços, muito além da OMC. Essas propostas são interessantes, uma vez que alguns dos temas que a UE já noticiou a serem negociados com o Mercosul, principalmente em serviços, já possuem propostas concretas nesse mega-acordo. Com isso, o objetivo deste trabalho é avaliar como o Brasil pode se utilizar dos novos padrões regulatórios que vêm sendo adotados para atingir coerência regulatória em serviços, para suas próprias negociações, a citar o acordo Mercosul - UE, a partir das propostas do bloco no TTIP; e os avanços até mesmo com a Aliança do Pacífico, que já adota o padrão TPP.

Palavras-chave: serviços; coerência regulatória; comércio internacional; mega-acordos; TPP; TTIP; Brasil. 


\begin{abstract}
Milena da Fonseca Azevedo. The regulation on Services and the Regulatory Coherence: An Interpretation of the Mega-Agreements from the Brazilian Perspective. 2018. 256 p. Master Degree - Faculdade de Direito, Universidade de São Paulo, São Paulo, 2018.
\end{abstract}

The regulatory coherence has emerged as theme constantly in the international trade agreements and negotiations. Because of the tariff reduction to very low levels, the regulatory barriers are the main focus of negotiations. This area is still turned to the regulation of goods while trade in services is still and area that needs regulatory advances. In a deep analysis of the agreements signed by Brazil, it was possible to note that some obligations under the Mercosur is to reach harmonization. This same obligation was incorporated in the agreements of economic complementation signed after Mercosur with other countries in the region. More recently, Brazil has signed an agreement with Peru in trade of services, investments and government procurement. This agreement, as publicized, was inspired on TPP. The services' provisions have obligations GATS-plus, among others, in domestic regulation and recognition. The TPP was the first mega-agreement signed and made public until now. Despite it is not in force, the TPP ended establishing a regulatory standard to the ongoing negotiations of international trade, including the regulatory coherence and taking the trade in services to another level. In parallel, the other megaagreement under negotiation between EU and USA is TTIP. This trade and investment agreement, if it ever be in force - up until now the negotiations are paralised - should contain provisions on cooperation and good regulatory practices and services, beyond the WTO standards. The proposals are interesting to the extent that some themes that the EU already notified that it is going to be negotiated with the Mercosur, especially in services, already have concret proposals in this mega-agreement. Therefore, the goal of this dissertation is to evaluate how Brazil can use of the regulatory patterns adopted to reach regulatory coherence in services, that exist at this moment, to its own negotiations, such as the agreement between EU - Mercosur, from the proposals EU in the TTIP and even advances with the Pacific Alliance that already adopts the TPP standards.

Key-words: services; regulatory coherence; international trade; mega agreements; TPP; TTIP; Brazil. 


\section{LISTA DE SIGLAS}

\begin{tabular}{|c|c|}
\hline AAP & Acordos de Alcance Parcial \\
\hline $\mathrm{ABNT}$ & Associação Brasileira de Normas Técnicas \\
\hline $\mathrm{ACE}$ & Acordo de Complementação Econômica \\
\hline ALADI & Associação Latino-Americana de Integração \\
\hline APEC & Cooperação Econômica Ásia-Pacífico \\
\hline $\mathrm{ARCs}$ & Acordos Regionais De Comércio \\
\hline ASEAN & Associação de Nações do Sudeste Asiático \\
\hline BRICS & Brasil, Rússia, Índia, China e África do Sul \\
\hline CAMEX & Câmara de Comércio Exterior \\
\hline CARICOM & Comunidade e Mercado Comum do Caribe \\
\hline CARI & \\
\hline FORUM & Fórum do Caribe \\
\hline CFTA & Área de Livre Comércio Continental Africana \\
\hline CGVs & Cadeias Globais de Valor \\
\hline CNI & Confederação Nacional da Indústria \\
\hline COMESA & Mercado Comum da África Oriental e Austral \\
\hline CUSFTA & Acordo de Livre Comércio entre o Canadá e os Estados Unidos \\
\hline EFTA & Associação Europeia de Livre Comércio \\
\hline EUA & Estados Unidos da América \\
\hline FAO & Organização das Nações Unidas para a Alimentação e a Agricultura \\
\hline FMI & Fundo Monetário Internacional \\
\hline G20 & Grupo dos 20 \\
\hline GATS & Acordo Geral sobre o Comércio de Serviços \\
\hline GATT & Acordo Geral de Tarifas e Comércio \\
\hline IAF & Foro Internacional de Credenciamento \\
\hline ICTSD & International Centre for Trade and Sustainable Development \\
\hline ILAC & Cooperação Internacional de Credenciamento de Laboratórios \\
\hline INMETRO & Instituto Nacional de Metrologia, Qualidade e Tecnologia \\
\hline ISO & Organização Internacional para Padronização \\
\hline ITU & União Internacional de Telecomunicações \\
\hline MDIC & Ministério da Indústria, Comércio Exterior e Serviços \\
\hline MERCO & \\
\hline SUL & Mercado Comum do Sul \\
\hline NAFTA & Tratado Norte-Americano de Livre Comércio \\
\hline OCDE & Organização para a Cooperação e Desenvolvimento Econômico \\
\hline OIE & Organização Mundial da Saúde Animal \\
\hline $\mathrm{OMC}$ & Organização Mundial do Comércio \\
\hline ONU & Organização das Nações Unidas \\
\hline PDs & Países Desenvolvidos \\
\hline PEDs & Países Em Desenvolvimento \\
\hline PIB & Produto Interno Bruto \\
\hline PMDRs & Países de Menor Desenvolvimento Relativo \\
\hline SACU & União Aduaneira da África Austral \\
\hline SGP & Sistema Geral de Preferências \\
\hline SISCOSERV & $\begin{array}{l}\text { Sistema Integrado de Comércio Exterior de Serviços, Intangíveis e } \\
\text { Outras Operações que Produzam Variações no Patrimônio }\end{array}$ \\
\hline
\end{tabular}


SPS Acordo sobre Medidas Sanitárias e Fitossanitárias

TBT

Acordo sobre Barreiras Técnicas ao Comércio

TISA

TPP

Acordo sobre o Comércio de Serviços

Acordo Transpacífico

TRIMS Acordo sobre Medidas de Investimento Relacionadas ao Comércio

TRIPS Acordo sobre Aspectos dos Direitos de Propriedade Intelectual

TTIP Acordo de Parceria Transatlântica de Comércio e Investimento

UE União Europeia

UNCITRAL Comissão das Nações Unidas para o Direito Mercantil Internacional

UNCTAD Conferência das Nações Unidas sobre Comércio e Desenvolvimento

WAEMU União Econômica e Monetária do Oeste Africano

WPDR Grupo de Trabalho em Regulação Doméstica 


\section{SUMÁRIO}

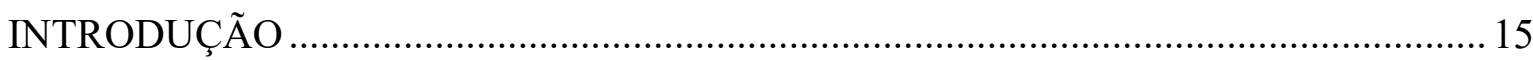

I. O CONCEITO DE COERÊNCIA REGULATÓRIA................................................. 22

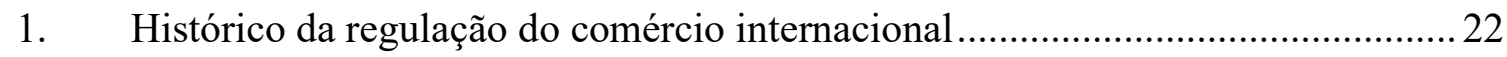

2. Como a $\mathrm{OMC}$ pode incorporar novas iniciativas regulatórias ................................ 30

3. Análise da coerência regulatória: conceitos, formas e benefícios.......................... 37

4. A coerência regulatória a partir dos dispositivos dos acordos ............................. 47

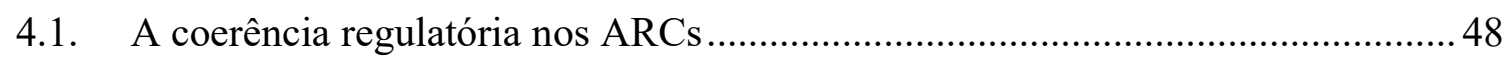

4.1.1. As obrigações de coerência nos ARCs do Brasil............................................56

4.2. A negociação de coerência regulatória nos mega-acordos ..................................67

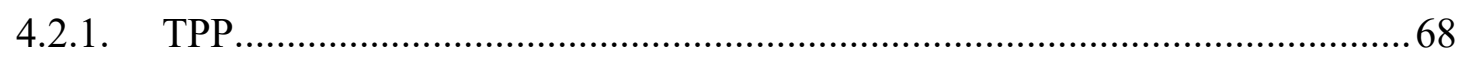

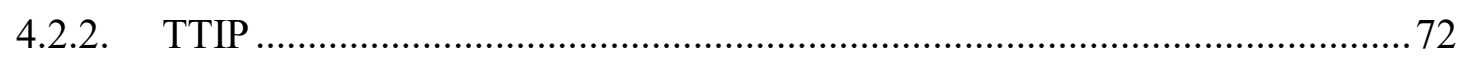

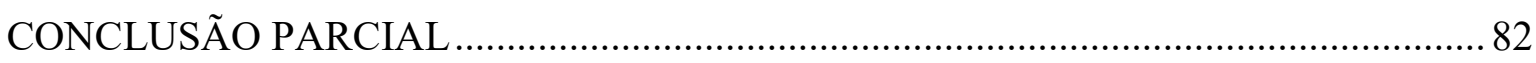

II. A REGULAMENTAÇÃO DO COMÉRCIO DE SERVIÇOS E A COERÊNCIA

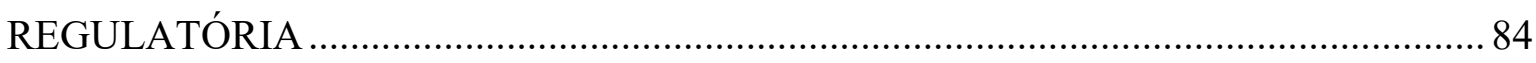

1. A coerência regulatória e o comércio de serviços................................................ 84

2. A regulamentação de serviços no comércio internacional .................................... 95

2.1. O Acordo GATS da OMC e as negociações da Rodada Doha ............................. 97

2.1.1. As negociações de serviços na Rodada Doha em regulação doméstica ...... 102

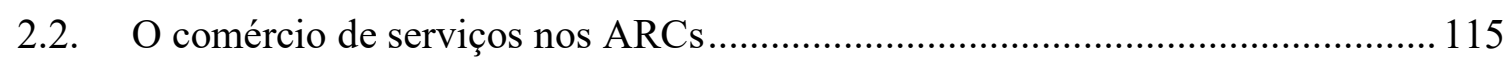

2.2.1. O comércio de serviços nos ARCs do Brasil .............................................. 120

2.3. O comércio de serviços nos mega-acordos ....................................................... 140

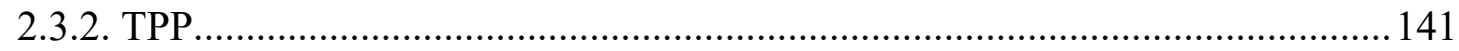

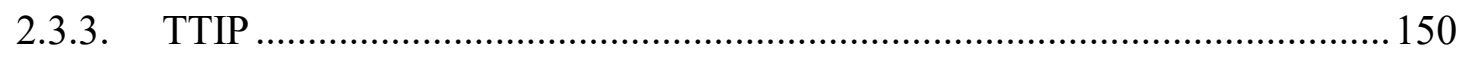

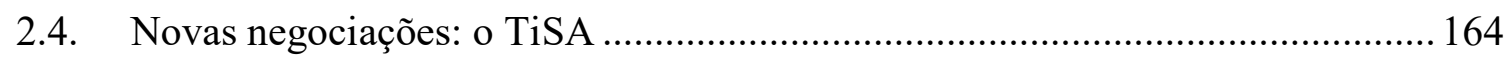

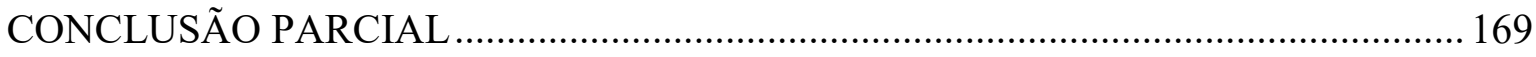

III. COMO OS PADRÕES REGULATÓRIOS DOS MEGA-ACORDOS PODEM SER USADOS COMO PADRÕES PARA NEGOCIAÇÕES DE SERVIÇOS DO BRASIL NA BUSCA POR COERÊNCIA REGULATÓRIA .............................................................. 172

1. A importância do comércio de serviços para o Brasil......................................... 173

2. Como o Brasil pode se utilizar dos padrões existentes para uma estratégia própria? 
2.1. A coerência regulatória

2.1.1. A comparação da regulação existente no Brasil com a regulação internacional 176

2.1.2. O padrão regulatório dos mega-acordos em coerência regulatória e os interesses brasileiros

2.2. O comércio de serviços 182

2.2.1. A comparação da regulação existente no Brasil com a regulação internacional 182

2.2.2. A construção de uma agenda regulatória internacional de serviços para o Brasil 188

2.2.3. Acesso a mercados a partir da balança comercial do Brasil em serviços .... 190

2.2.1. O padrão regulatório dos mega-acordos em serviços e os interesses brasileiros

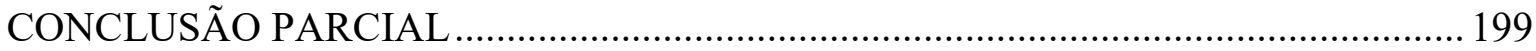

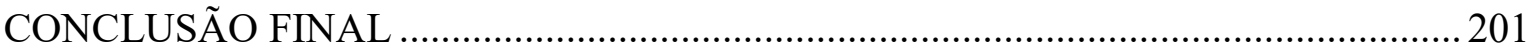

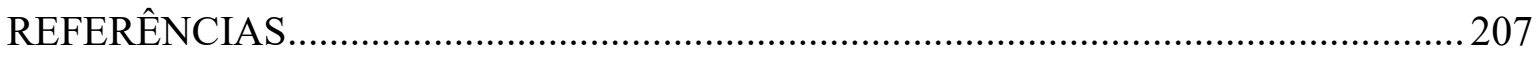

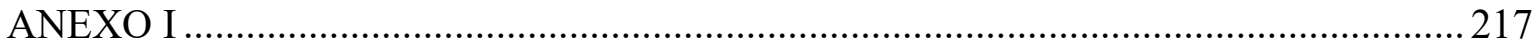

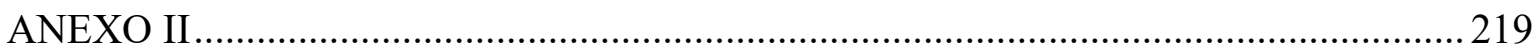

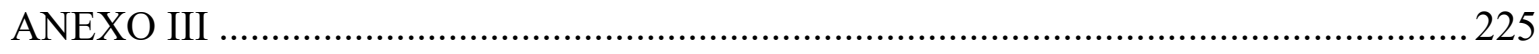

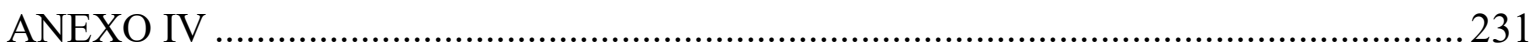

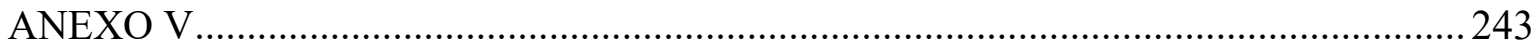




\section{INTRODUÇÃO}

Após grandes conquistas no Sistema Multilateral de Comércio com a diminuição das tarifas, as grandes disputas entre os países têm sido relacionadas a barreiras não tarifárias, que englobam, dentre outras, as barreiras regulatórias. Esses entraves estão, na maioria das vezes, formalizados por meio de legislação editada pelos países justamente para restringir acesso a mercados, representando barreiras ainda mais graves do que as tarifárias, por serem de difícil mensuração e identificação, uma vez que não raras são as vezes que tais barreiras se encontram camufladas por regulações internas tendentes à proteção do meio ambiente ou de direitos humanos e sociais.

Muito embora o tema da harmonização e coerência regulatórias remonte às tentativas de incentivar o comércio nas regiões do Norte da África, Oriente Médio e Europa Meridional com a padronização de pesos e medidas nos anos antes de Cristo (BRAITHWAITE E DRAHOS: 2000,4), a regulação, tal como se conhece atualmente no Direito Internacional, foi introduzida primeiramente pelo Acordo Geral de Tarifas e Comércio (GATT) e, posteriormente, aprimorada no âmbito da Organização Mundial do Comércio (OMC), após a Rodada Uruguai. Hoje, mais extensivamente, esses temas são regulados de forma cada vez mais abrangente nos Acordos Regionais de Comércio (ARCs) e mega-acordos ${ }^{1}$, como a Parceria Transpacífico (TPP) e Acordo de Parceria Transatlântica de Comércio e Investimento (TTIP).

\footnotetext{
${ }^{1}$ Os mega-acordos são assim chamados pelo volume de comércio que envolvem, o número de países que participam desses acordos, bem como a variedade de matérias que os recobrem.

Bull, Mahboubi, Stewart et. al $(2015,2)$, "These proposed mega-regional agreements not only aim to further reduce tariffs (in the case of TPP, to zero) and other border measures that impede trade, but they also contain ambitious arrangements for regulatory cooperation to address trade barriers created by divergent regulatory measures and approaches for goods and services; deal with other structural barriers such as those created by government procurement policies and stateowned enterprises; address global supply chains, e-commerce, competition policy, transparency, and anti-corruption; and enhance protection for investment and intellectual property. The regimes' wide range of subjects and their ambitious scope justify the label "mega-regional.". Além deste, Ricardo Meléndez-Ortiz $(2014,13)$ define acordos mega-regionais como: "Mega-regional RTAs, deep integration partnerships in the form of RTAs between countries or regions with a major share of world trade and FDI and in which two or more of the parties are in a paramount driver position, or serve as hubs, in global value chains (i.e. the US, the EU, Japan, China). This category includes ongoing negotiations in the TPP; the emerging TTIP between the EU and the US; and potentially the RCEP, between the 10 ASEAN countries and six of its RTA partners: China, India, Japan, South Korea, Australia and New Zealand. Beyond market access, emphasis in this integration is on the quest for regulatory compatibility and a rules basket aimed at ironing out differences in investment and business climates."
} 
Apesar de a busca pela coerência regulatória não ser algo inédito, as discussões acerca da questão têm sido cada vez mais recorrentes no comércio internacional em razão da tentativa dos países de diminuírem as barreiras não tarifárias e buscarem alternativas para a integração no comércio internacional com a multiplicação das Cadeias Globais de Valor (CGVs).

Segundo a Global Value Chain Initiative, as CGVs compreendem todas as atividades que as empresas e trabalhadores exercem para a concepção final de um produto. Isso inclui atividades de design, produção, marketing, distribuição e suporte ao consumidor final. Essas atividades podem estar em uma única empresa ou dividida em diversas delas, podendo também ser uma cadeia de produção de bens ou serviços. Do mesmo modo, tais atividades podem ser exercidas em uma localidade geográfica ou espalhadas em diversas regiões, o que as caracterizaria como "global"2.

Essa forma de organização industrial, porém, só foi possível, em razão da redução significativa de tarifas nos últimos anos, da integração do comércio internacional e do desenvolvimento de novos serviços que permitem a comunicação instantânea, o comércio célere de bens e as trocas financeiras. Portanto, a fragmentação da produção só foi possível em decorrência da evolução do comércio internacional, bem como o desenvolvimento de tecnologias que tornassem viável econômica e fisicamente a circulação eficiente de mercadorias.

Historicamente, a regulação do comércio internacional e, consequentemente, a coerência e convergência regulatórias, estavam, a princípio, bastante relacionadas ao comércio de bens. Até mesmo no âmbito da OMC, a busca por coerência e boas práticas regulatórias relacionavam-se de forma mais estreita aos acordos sobre Barreiras Técnicas ao Comércio (TBT) e Acordo sobre Medidas Sanitárias e Fitossanitárias (SPS). No entanto, a partir dos anos 1990, com a evolução tecnológica e a pressão dos países desenvolvidos (PDs), o comércio de serviços passou a ganhar uma grande importância no comércio internacional, justamente por conta das $\mathrm{CGVs}$, para as quais é fundamental a rápida circulação de bens, o pagamento de serviços e a comunicação entre os agentes.

\footnotetext{
${ }^{2}$ Disponível em: <http/s://globalvaluechains.org/concept-tools>. Acesso em: 17 jan. 2016. 
Em discurso no Global Services Summit em Washington D.C. em 17 de outubro de 2017, o Diretor Geral da OMC, Roberto Azevêdo, ressaltou a importância do comércio de serviços, bem como as iniciativas havidas, até o momento, para avançar nesse tópico ${ }^{3}$. O comércio de serviços é responsável por mais de dois terços do PIB mundial e atrai quase dois terços do investimento direto estrangeiro global. Para a maior parte dos países, os serviços correspondem à maior parcela da produção nacional e da taxa de emprego.

A exportação de serviços mundial chegou a 4,8 trilhões de dólares em 2016, correspondendo a mais de $23 \%$ do comércio mundial total. Atualmente, o comércio de serviços em valor adicionado corresponde a quase $50 \%$ do comércio mundial ${ }^{4}$. Essa análise demonstra como serviços são facilitadores das CGVs, pois, sem os serviços transfronteiriços, seria impossível coordenar a produção por etapas em diferentes países, o que envolve logística, comunicação e serviços financeiros, principalmente finanças comerciais e pagamentos eletrônicos. Nesse sentido, a eficiência dos serviços é determinante para o desempenho exportador.

Rentzhog e Anér (2014: 2-4) traçam as principais mudanças ocorridas no campo de serviços em decorrência das mudanças tecnológicas. Primeiramente na produção, em razão do fenômeno que ocasionou a "desindustrialização da indústria", a qual, segundo os autores, consistiria no crescimento do consumo de serviços, em razão do advento tecnológico, uma vez que os bens passaram a vir acompanhados da prestação de diversos deles. A segunda mudança teria ocorrido no comportamento da própria produção, chamado de "servicificação" (servicification, em inglês), ou seja, setores alheios a áreas de serviços estariam cada vez mais adquirindo, produzindo e vendendo serviços como parte do pacote de bens. Esse fenômeno dever-se-ia ao aumento da dispersão geográfica da produção com as CGVs, aumento da eficiência, aumento da relação com consumidores no fornecimento de serviços direcionados a seus produtos e meio de diferenciação dos produtos como vantagem frente ao consumidor.

\footnotetext{
3 Azevêdo underlines growing importance of services in global trade. Disponível em: $<$ https://www.wto.org/english/news_e/spra_e/spra193_e.htm>. Acesso em: 23 out.2017.

4 Op. Cit. 3 e World Trade Statistics Review 2017. Disponível em: <https://www.wto.org/ english/res_e/statis_e/wts2017_e/wts2017_e.pdf>.
} 
Apesar de a relação entre o tema dos serviços e as CGVs ser evidente e cada vez mais recorrente, nota-se indiscutível carência de avanços regulatórios no âmbito dos Acordos da OMC, em vista do travamento da Rodada Doha. Como visto, se a preocupação da coerência regulatória é combater as barreiras não tarifárias, faz-se necessário avaliar como a regulação de serviços pode ser feita para permitir acesso a mercado.

A coerência regulatória é um tema fundamental para o comércio de serviços e está diretamente ligada à liberalização em razão de seus tipos de barreiras não serem tarifários. Porém, além disso, há temas que somente podem avançar no comércio de serviços se estivermos diante da melhor forma de regulação, ou ainda, se houver coerência entre os temas regulados. Tendo em vista que o comércio de serviços é puramente regulatório, discriminações regulatórias podem ser extremamente deletérias ao processo de liberalização. Nesse sentido, a definição de critérios de regulação interna e a proibição aos países na regulação dos temas sem critérios mínimos de transparência, objetividade, igualdade, permitirão o livre fluxo de comércio em serviços.

Esse cenário de inércia regulatória no âmbito da $\mathrm{OMC}$ propiciou nos últimos anos o aumento de ARCs e da negociação em andamento dos mega-acordos. Conforme o gráfico abaixo ilustra, a entrada em vigor de acordos de serviços aumentou exponencialmente desde os anos 1990. 
Gráfico I: ARCs atualmente em vigor (de acordo com o ano de entrada em vigor) 1948-2017

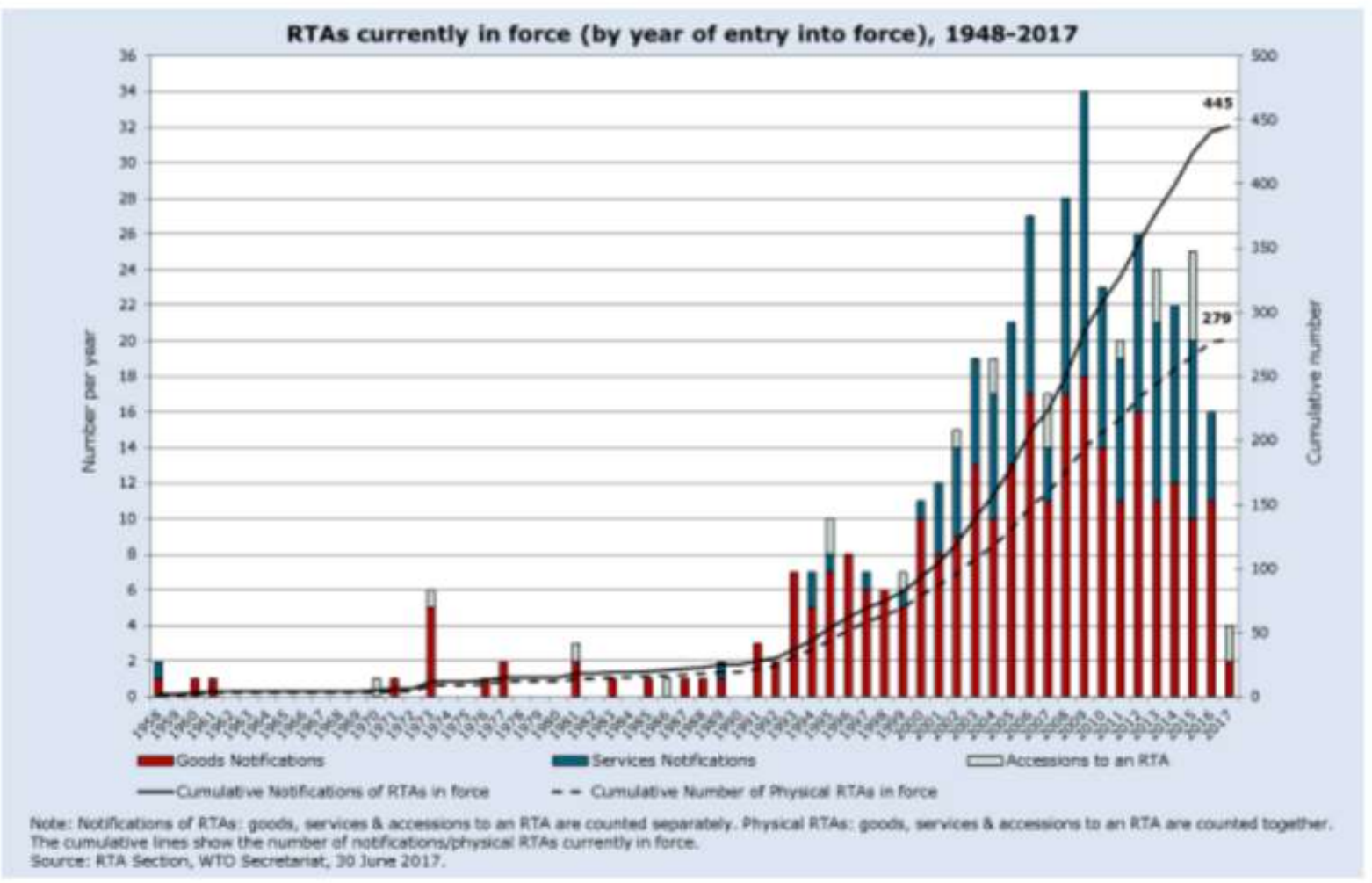

Fonte: OMC (<https://www.wto.org/english/tratop_e/region_e/rtajan-june17_e.pdf $>$ ).

Segundo Carneiro $(2015,12)$, os países aos quais interessa maior integração às CGVs se veem obrigados a buscar outras formas de atender à demanda exigida pela fragmentação da produção, especialmente em acordos profundos de comércio e investimentos - que incluem um extenso rol de disciplinas, com o objetivo de não só liberalizar fluxos de bens, serviços e investimentos, mas também remover um conjunto de obstáculos a esses fluxos que decorrem da inconsistência entre normas, regulamentos, padrões e procedimentos existentes nos diferentes países, de maneira a consolidar um verdadeiro espaço econômico ampliado no qual a produção dispersa de bens e serviços pode funcionar sem interrupções.

Nesse contexto, tais acordos compreendem uma vasta gama de temas que antes não eram regulados na OMC e, nem mesmo, nos ARCs, como é o caso da inserção de capítulos de cooperação e coerência regulatória em acordos como o TPP e o TTIP. 
Não diferente, os mega-acordos também regulam o comércio de serviços e, como se verá ao longo do presente estudo, vão além dos dispositivos existentes nos Acordos da OMC, com a inclusão de previsões, como, por exemplo, sobre comércio eletrônico, tema que há tempos aguarda um avanço multilateral.

Em face desse cenário internacional, o Brasil, neste momento, está investindo em novas negociações de ARCs, como a expansão do acordo com o México, negociações com o Canadá, Associação Europeia de Livre Comércio (EFTA), Coreia do Sul, Japão, entre outros, bem como está o país próximo de concluir um acordo entre Mercado Comum do Sul (Mercosul) e União Europeia (UE), ainda em andamento quando do desenvolvimento do presente estudo. Como se sabe, os ARCs englobam uma diversidade de temas, incluindo serviços, sendo essa questão, cada vez mais, imprescindível nas negociações com dispositivos mais completos e abrangentes. Diante de um cenário internacional de crescente importância do comércio e amplificação dos temas reguladores de serviços, torna-se importante ter uma estratégia clara para a negociação de acordos, ainda que serviços, historicamente, não sejam uma área de interesses em que o Brasil tenha uma posição mais ofensiva.

Assim, dada a importância atual e cada vez mais crescente dos temas da coerência regulatória e do comércio de serviços, assim como a relação entre eles, ambos serão objeto do presente estudo, que tem como base a seguinte hipótese: diante da falta de avanços no âmbito dos Acordos da OMC e da proliferação das redes produtivas formadas pelas CGVs, a regulação do comércio de serviços, tal como vem sendo feita por meio dos chamados megaacordos, os quais buscam, de forma crescente, a coerência regulatória, tornou-se necessária para o fortalecimento dos novos modelos de comércio internacional. Nesse contexto, a tese é de que o Brasil, como um país que mudou recentemente sua estratégia de comércio internacional, deve observar os parâmetros regulatórios negociados nos referidos megaacordos a fim de buscar uma estratégia de negociação para as novas iniciativas empreendidas pelo País que busque encampar os interesses locais e, assim, ter uma estratégia ofensiva, ao invés de reativa, às novidades já presentes nos marcos regulatórios internacionais de serviços, de forma a se beneficiar das novas modalidades de comércio representadas pelas CGVs. 
Para tanto, o Primeiro Capítulo trará um breve histórico acerca do tema da coerência regulatória no Direito do Comércio Internacional, bem como de seu conceito, formato, e análise dos custos e benefícios de sua implementação. Ainda, serão estudados os dispositivos dos acordos da OMC, ARCs, da legislação brasileira, assim como de países selecionados e dos mega-acordos - TPP e TTIP a respeito do tema da coerência regulatória.

Em seguida, no Segundo Capítulo, será estudado como essa coerência regulatória avançou no comércio de serviços, com o estudo e mapeamento da regulação internacional de serviços nos diversos foros que tratam desse assunto: (i) OMC, com a análise do Acordo Geral sobre o Comércio de Serviços (GATS), propostas de países selecionados na Rodada Doha para modificações ao Acordo GATS e novas iniciativas no âmbito na OMC, como o Acordo de Facilitação de Comércio de Serviços; (ii) ARCs selecionados que trazem o comércio de serviços, incluindo análise mais profunda de acordos já assinados pelo Brasil como o Mercosul, acordo Mercosul-Chile e o acordo Brasil-Peru; (iii) mega-acordos - TPP e TTIP; e (iv) informações públicas do Acordo sobre o Comércio de Serviços (TiSA) que permitam auferir o andamento do acordo no que tange ao tema aqui estudado.

Uma vez estudados os temas da coerência regulatória e da regulação no comércio de serviços, o Terceiro e último Capítulo analisa como referidos temas dialogam entre si e, com isso, verifica-se como o Brasil poderia se utilizar dos padrões regulatórios hoje existentes e discutidos nos principais acordos internacionais para suas negociações no assunto de serviços. 


\section{CONCLUSÃO FINAL}

A partir da análise histórica traçada no presente estudo, constatou-se que a coerência regulatória foi um movimento natural à formação das regras de comércio internacional. Com o passar dos anos, as mudanças regulatórias foram impulsionadas, em grande parte, pelos novos modelos de comércio, em especial pela fragmentação da produção e formação das CGVs, as quais demandam integração da produção em níveis cada vez maiores e mais dinâmicos.

Com o advento do GATT, houve o estabelecimento de parâmetros mínimos a serem respeitados pelos Estados, como os princípios da não discriminação e do tratamento nacional, dentre outros, bem como a necessidade de redução de tarifas (shallow integration). Nesse momento, havia resistência dos PEDs em avançar nos temas de natureza regulatória, uma vez que era do interesse desses países manter determinadas políticas públicas e garantir

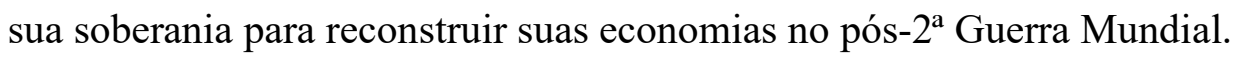

Anos depois, no âmbito da Rodada Uruguai, foi estabelecido um Sistema Multilateral de Comércio com os Acordos da OMC, que possuem, de certa forma, iniciativas de harmonização e boas práticas regulatórias (deep integration), ainda que de forma tímida e focada em determinados setores. Nesse período de criação recente da $\mathrm{OMC}$, o comércio já havia alcançado níveis satisfatórios de redução de tarifas, mas ainda não considerava temas relacionados à regulação não tarifária do comércio internacional.

Como depois da Rodada Uruguai não houve avanços significativos no âmbito da OMC na Rodada Doha, os progressos mais expressivos passaram a ser alcançados no âmbito dos ARCs. Com as negociações entre PDs e PEDs, estes, que eram, até a Rodada Uruguai, resistentes a avanços regulatórios, passaram a aderir à discussão desse tema em razão da adesão aos modelos dos PDs; ou, em alguns casos, para regular temas de interesse interno desses países que não evoluíram no âmbito das negociações da OMC. Com isso, a necessidade de convergência entre as legislações internacional e nacional foi se tornando parte importante na agenda de negociações internacionais. 
Com esse avanço acontecendo longe do âmbito multilateral da $\mathrm{OMC}$, os Estados passaram a negociar os mega-acordos como uma resposta para dar eficiência a esses fluxos de comércio.

A análise histórica empreendida no Capítulo I permitiu verificar essas nuances por meio da análise dos acordos e padrões regulatórios. Foi apenas com os mega-acordos que a preocupação com a forma de implementação da regulação se apresentou. Nesse aspecto, tanto o TPP quanto o TTIP apresentam princípios para a edição de normas, bem como estabelecem, nos capítulos temáticos - como o de serviços -, formas em que se permite a adoção da coerência regulatória e a edição de regras mais objetivas, transparentes e não discriminatórias.

A coerência regulatória nos termos negociados no acordo TPP refere-se ao uso de boas práticas no processo de planejamento, desenho, lançamento, implementação e regulação de medidas para facilitar o cumprimento dos objetivos de políticas domésticas e esforços governamentais de incentivo à cooperação regulatória para aprofundar esses objetivos e promover o comércio internacional e investimento, crescimento econômico e emprego. Já no âmbito do acordo TTIP, trata-se de cooperação regulatória, de modo que as autoridades locais trabalhem juntas para assegurar altos níveis de proteção dos objetivos de políticas públicas. Além da cooperação regulatória, a UE propõe boas práticas regulatórias com o fim de promover princípios para o desenvolvimento e implementação de regulação de bens e serviços de alta qualidade, eficiente e efetiva, como transparência, previsibilidade e prestação de contas (accountability). Esses conceitos se aplicam ao desenvolvimento de todas as regras de comércio, incluindo aquelas de serviços.

Como a dinâmica do comércio internacional, principalmente representada pelas CGVs, demonstra que o comércio de serviços tem papel preponderante, o tema regulatório nesse tocante ainda carece de evolução para acompanhar os novos modelos de comércio. Essa análise, desenvolvida ao longo do Capítulo II, evidenciou que, apenas com a criação do Acordo GATS no âmbito da OMC, foi que a regulação dos serviços passou a existir, contribuindo por ser o primeiro marco regulatório a traçar os princípios e as regras gerais aplicadas ao comércio de serviços, em especial no tocante às barreiras regulatórias e na busca pelos melhores métodos regulatórios não discriminatórios. 
No Acordo GATS, se destacam os dispositivos de nação mais favorecida (Artigo II), tratamento nacional (Artigo XVII) e acesso a mercado (Artigo XVI), que instituem as condições de liberalização, enquanto a regulamentação doméstica (Artigo VI), bem como transparência (Artigo III), demarcam a atuação dos agentes internos no Estado ao estabelecerem medidas para a atuação dos provedores de serviços e, portanto, evitam que as medidas internas sejam transformadas em barreiras ao comércio. Ainda, o Artigo VII (reconhecimento mútuo) prevê as condições para o reconhecimento de qualificações e certificações profissionais de Membros, o que, além de permitir o acesso a mercados, estabelece os termos regulatórios que podem permitir esse arranjo por meio da assinatura de acordos de reconhecimento mútuo.

Contudo, esses dispositivos, embora importantes, precisam de avanços com vistas à realidade do comércio atual, representada pelo modo de produção em CGVs. Não há, no momento, perspectivas de que as negociações na OMC tragam algum resultado nessa direção, embora os Membros tenham apresentado propostas inovadoras. Uma delas é o acordo de facilitação de serviços, o qual prevê: (i) mecanismos de transparência e publicidade, permitindo às Partes maior conhecimento da regulação em vigor em outros países; (ii) teste de necessidade econômica que impediria a implementação de medidas de forma discriminatória; (iii) disposições de reconhecimento com procedimentos adequados para avaliação de requisitos e verificação de qualificação, o que poderia facilitar a negociação de acordos de reconhecimento mútuo; e (iv) mecanismos de cooperação e assistência técnica para PEDs e PMDRs.

Além dessa proposta, outra forma com potencial de avanço na regulação de serviços na OMC poderia se dar por meio do TiSA. Porém, como as negociações estavam sendo lideradas pelos EUA, tendo em vista a atual mudança de política comercial daquele país, o futuro desse acordo e seu potencial na OMC é incerto.

Se, de um lado, não há perspectivas de mudanças nos Acordos da $\mathrm{OMC}$, de outro, os ARCs incorporaram, em proporções cada vez maiores, disposições em serviços. No entanto, notou-se que o avanço regulatório de serviços nesses acordos foi incipiente do ponto de vista de regras, uma vez que muitos simplesmente reproduziram o Acordo GATS, outros possuem 
dispositivos ainda menos vinculantes e apenas alguns vão além do acordo de serviços da OMC. Dessa forma, nos temas regulatórios, os avanços não ocorreram de forma a criar um ambiente liberalizante e com impulso pela busca de coerência regulatória.

Por outro lado, os mega-acordos consolidaram melhorias importantes na regulação de serviços pela busca de um padrão único que permitisse a fluidez do comércio. Em suma, pode-se destacar pela análise dos capítulos de serviços do TPP e a proposta de capítulo de serviços no TTIP que os padrões regulatórios gerais do Acordo GATS - princípio de não discriminação, acesso a mercados, regulação doméstica, transparência e reconhecimento foram consolidados, tendo o texto dos acordos inovado em questões setoriais e nos capítulos específicos de serviços.

Nesse sentido, o capítulo de comércio eletrônico do TPP tem diversas formas de busca pela coerência regulatória, destacando-se a implementação horizontal em transações domésticas eletrônicas dos princípios das UNCITRAL Model Law on Electronic Commerce 1996 ou the United Nations Convention on the Use of Electronic Communications in International Contracts. Outro aspecto que merece destaque é a inserção no TPP de um capítulo de serviços profissionais que prevê diálogos de reconhecimento de qualificação, licença e registro profissional.

No TTIP, as questões regulatórias ganham um alto grau de detalhamento. Com relação à regulação doméstica, por exemplo, um capítulo específico e anexo foram dedicados à criação de um modelo de acordo de reconhecimento mútuo para qualificações, certificações e licenças profissionais.

Os mega-acordos possuem, portanto, um aparato regulatório bastante além das normas da OMC.

Muito embora não faça parte da lista de países que negociam esses mega-acordos, o Brasil, país que tem como base da política comercial internacional as regras da $\mathrm{OMC}$, tem seus parâmetros regulatórios em serviços bastante defasados frente às inovações regulatórias que vem sendo transacionadas no cenário internacional. 
Ao analisar a estatística de serviços do Brasil, nota-se o quanto o país pode avançar no fornecimento de serviços, uma vez que sua participação ainda é irrisória. Para ilustrar, o Brasil alcança a $32^{\mathrm{a}}$ posição entre os maiores exportadores de serviços, enquanto seus pares no BRICS, China e Índia, figuram entre os 10 maiores exportadores mundiais.

Ressalte-se, ainda, que os países com os quais o Brasil mais transaciona em serviços - países europeus, parte englobada pela UE e outra pelo EFTA e EUA - não possuem ainda acordos firmados com o país. Portanto, uma estratégia de negociação de acordos com os países com os quais o Brasil mais tem relacionamento comercial poderia servir de incentivo às exportações. Entretanto, isso só será possível se criado um ambiente regulatório propício ao crescimento dessa área no comércio internacional do Brasil.

A esse respeito, é complexa a tarefa de delimitar uma agenda regulatória em serviços tendo em vista as particularidades de cada setor. Por isso, o desenho de uma agenda negociadora para o Brasil no campo dos acordos comerciais de serviços depende dos objetivos e prioridades do País. Se o objetivo for sua maior inserção no comércio internacional, as estratégias brasileiras devem ser orientadas por três ordens: (i) remover barreiras ao comércio em mercados relevantes e promissores para as exportações brasileiras; (ii) aumentar a oferta, no mercado brasileiro, de serviços de qualidade a preços competitivos por meio da redução das barreiras à importação no País; e não menos importante; (iii) fomentar a maior produtividade e competitividade do setor de serviços brasileiro, possibilitando a geração de empregos mais qualificados e maior renda no país (CNI, 2016: 47).

Com relação às regras gerais, o TTIP pode contribuir com os padrões de regulação doméstica, que são bastante detalhados, e com modelos sobre como avançar em acordos de reconhecimento mútuo. Por outro lado, o TPP se destaca na previsão de formas de coerência nos setores específicos, como comércio eletrônico e serviços profissionais.

Fato é que a coerência regulatória e o comércio de serviços são temas que passarão a ser imprescindíveis nos acordos de comércio. Os mega-acordos, mais especificamente o TPP e o que indica as propostas do TTIP, foram capazes de traduzir em regras as necessidades das CGVs, quais sejam: um modelo regulatório eficiente e não discriminatório que permita 
a livre circulação de bens e serviços, preocupando-se não apenas com tarifas, mas criando dispositivos que propiciassem a criação de normas de forma clara, objetiva, transparente e com base em requisitos mínimos.

O Brasil tem um longo caminho a percorrer, com vistas a cobrir os interesses ofensivos do país na área. Sobre isso, será necessário decidir sobre os objetivos internos que se pretendem alcançar. Os mega-acordos poderiam trazer uma contribuição imprescindível nesse sentido. 


\section{REFERÊNCIAS}

AMCHAM Brasil. Alternativas do Brasil: UE e/ou EUA: essas parcerias são excludentes ou complementares? Disponível em: < https://www.amcham.com.br/noticias/competitividade/brasil-deve-investir-em-acordoscomerciais-com-eua-e-ue-aponta-estudo-amcham-fgv-8683.html>. Acesso em 10 out. 2017.

ARVÍUS, Christer; JACHIA, Lorenza. Regulatory Cooperation: A Wikihow. E15Initiative. Geneva: International Centre for Trade and Sustainable Development (ICTSD) and World Economic Forum, 2015.

AZEVEDO, Milena da Fonseca. O desafio dos novos padrões regulatórios nos acordos preferenciais de comércio para estratégia multilateral brasileira em serviços e propriedade intelectual. FAPESP: SP, 2012.

BALDWIN, Richard. Global supply chains: why they emerged, why they matter, and where they are going. In: Elms, Deborah K. e Low, Patrick. Global value chains in a changing world. Geneva: Fung Global Institute (FGI), Nanyang Technological University (NTU), and World Trade Organization (WTO), 2013, p. 13- 60.

; EVENETT, Simon; e LOW, Patrick. Beyond Tariffs: multilateralizing non-tariff RTA commitments. In: BALDWIN, R.; LOW, P. Multilateralizing Regionalism: Challenges for the Global Trading System, WTO, 2009, p.79 - 141.

BALDWIN, Robert; CAVE, Martin; LODGE, Martin. The Oxford Handbook of Regulation. Oxford: Oxford University Press, 2013, p. 3 -16; 407-433; 613-626.

BRAITHWAITE, John; DRAHOS, Peter. Global Business Regulation. Cambridge: Cambridge University Press, 2000.

BOLLYKY, Thomas. A Role for the World Trade Organization on Regulatory Coherence. E15Initiative. Geneva: International Centre for Trade and Sustainable Development (ICTSD) and World Economic Forum, 2015.

BORGES, Karla Cristina Martins. O GATS, seu Artigo IV, o processo de liberalização e o incremento da participação do Brasil no comércio internacional. In: CELLI JR., Umberto e SAYEG, Fernanda Manzano. Comércio de Serviços, OMC e Desenvolvimento. São Paulo: IDCID, 2008.

BULL, Reeve T. Developing A Domestic Framework For International Regulatory Cooperation. Law and Contemporary Problems. Vol. 78, 49 - 74. 
BULL, Reeve T; MAHBOUBI, Neysun A.; STEWART, Richard B. et. al. New Approaches to International Regulatory cooperation: The challenge of TTIP, TPP, and Mega-regional trade Agreements. Law and Contemporary Problems. Vol. 78, 1-29.

CARNEIRO, Flavio Lyrio. Parceria Trans-Pacífico: Um Acordo Megarregional Na Fronteira Da Regulação Do Comércio Internacional? Texto para Discussão 2108. Brasília, julho de 2015.

CATTANEO, Olivier. Promoting Greater Regulatory Coherence and Cooperation through Aid for Trade: What Could Be Done? What Role for the Private Sector and the WTO? E15Initiative. Geneva: International Centre for Trade and Sustainable Development (ICTSD) and World Economic Forum, 2015.

FINK, Carsten and JANSEN, Marion. Services provisions in regional trade agreements: stumbling blocks or building blocks for multilateral liberalization? In: Baldwin, Richard and Low, Patrick. Multilateralizing regionalism: challenges for the global trading system. New York: Cambridge University Press, 2009. P. 221-261.

CELLI JUNIOR, U. Comércio de Serviços na OMC - Liberalização, condições e desafios. $1^{\mathrm{a}}$. ed. Curitiba: Juruá, 2009. v. 1. 256 p.

CESAR DE OLIVEIRA, S. E. M. Cadeias globais de valor e os novos padrões de comércio internacional: uma análise comparada das estratégias de inserção de Brasil e Canadá. Tese de Doutorado. Universidade de Brasília: Brasília, 2014.

CHARNOVITZ, Steve. US Efforts to Ensure that Regulation Does Not Present Trade Barriers. E15Initiative. Geneva: International Centre for Trade and Sustainable Development (ICTSD) and World Economic Forum, 2015.

CUNHA, Raphael Coutinho. Negociações comerciais em uma economia fechada: o Brasil e o comércio de serviços na Rodada Uruguai. Rev. Bras. Polít. Int. 58 (1): 142-163 [2015].

DRAKE-BROCKMAN, Jane e STEPHENSON, Sherry. Implications for 21st Century Trade and Development of the Emergence of Services Value Chains. Study for the International Centre for Trade and Sustainable Development, 2012. Disponível em: $<$ http://ictsd.org/downloads/2012/11/implications-for-21stcentury-trade-and-developmentof-the-emergence-ofservices-value-chains.pdf>. Acesso em: 02 maio 2016. 
PRADO, Mariana Mota e BERTRAND, Vladimir. Regulatory Cooperation on Latin America: The Case of Mercosur. Law and Contemporary Problems. Vol. 78: 205, p. 205 -230 .

DUNOFF, Jefrey L. Mapping a Hidden World of International Regulatory Cooperation. Law and Contemporary Problems. Vol. 78, p. 267 - 299.

FREUND, Caroline. Other New Areas: Customs Administration and Trade Facilitation, Anticorruption, Small and Medium-Sized Enterprises, and More. In: SCHOTT, Jeffrey J. e CIMINO-ISAACS, Cathleen. Assessing The Trans-Pacific Partnership: Volume 2: Innovations in Trading Rules. Peterson Institute for International Economics. PIIE Briefing 16-4: March, 2016.

GARI, Gabriel. The liberalisation of trade in services in Mercosur. (Cameron May, 2009), 269 pages.

GELPERN, Anna. Financial Services. In: Assessing The Trans-Pacific Partnership: Volume 1: Market Access and Sectoral Issues. Peterson Institute for International Economics. PIIE Briefing 16-1: February, 2016.

GOOTIZ, Batshur; MATTOO, Aaditya. Services in the Trans-Pacific Partnership: What Would Be Lost? World Bank Group. Development Research Group Trade and International Integration Team February 2017. Policy Research Working Paper 7964.

HEES, Felipe. Negociações multi- e plurilaterais sobre serviços: algumas considerações. Pontes, Volume 13 - Número 1, 7 de março de 2017. Disponível em: $<$ https://www.ictsd.org/bridges-news/pontes/news/negociações-multi-e-plurilaterais-sobreserviços-algumas-considerações $>$. Acesso em: 13 out. 2017.

HUFBAUER, Gary; STEPHENSON, Sherry. SERVICES TRADE: PAST LIBERALIZATION AND FUTURE CHALLENGES. Journal of International Economic Law 10(3), 605-630 doi:10.1093/jiel/jgm028. Advance Access publication 10 August 2007.

HOEKMAN, Bernard. Trade Agreements and International Regulatory Cooperation in a Supply Chain World. Italy: European University Institute Robert Schuman Centre for Advanced Studies Global Governance Programme, 2014.

Supply Chains, Mega-Regionals and Multilateralism: A Road Map for the WTO. Centre for Economic Policy Research: Abril 2014. 
HOEKMAN, Bernard; MAVROIDIS, Petros C. Regulatory Spillovers and the Trading System: From Coherence to Cooperation. E15Initiative. Geneva: International Centre for Trade and Sustainable Development (ICTSD) and World Economic Forum, 2015. $<$ www.e15initiative.org/>.

; KOSTECKI, Michel M. The Polítical Economy of the World Trading System: The WTO and Beyond. Second Edition. New York: Oxford University Press, 2003.

HORN, H.; MAVROIDIS P.; SAPIR A. Beyond the WTO - An anatomy of EU and US preferential trade agreements. Bruegel Blueprint Series: 2009.

HOWSE, Robert. Regulatory Cooperation, Regional trade agreements, and World trade law: conflict or Complementarity? Law And Contemporary Problems. Vol. 78:137, 137-151.

HUFBAUER, Gary Clide. Liberalization of services. In: Assessing The Trans-Pacific Partnership: Volume 1: Market Access and Sectoral Issues. Peterson Institute for International Economics. PIIE Briefing 16-1: February, 2016.

KAUFFMANN, Céline e MALYSHEV, Nikolai. International Regulatory Cooperation: The Menu of Approaches. E15Initiative. Geneva: International Centre for Trade and Sustainable Development (ICTSD) and World Economic Forum, 2015.

LIM, AIK HOE e DE MEESTER, BART. An introduction to domestic regulation and GATS. In: LIM, AIK HOE e DE MEESTER, BART(ed.). WTO Domestic Regulation and Services Trade: Putting Principles into Practice. Cambridge: Cambridge University Press, 2014.

LOW, Patrick. WTO Decision-Making for the Future. World Trade Organization Economic Research and Statistics Division. Staff Working Paper ERSD-2011-05 de 02 de maio de 2011. Disponível em: $<$ https://www.wto.org/english/res_e/reser_e/ersd201105_e.pdf $>$. Acesso em: 02 nov. 2017.

MATTOO, Aaditya. Services Trade and Regulatory Cooperation. E15 Initiative. Geneva: International Centre for Trade and Sustainable Development (ICTSD) and World Economic Forum, 2015. Disponível em: $<$ www.e15initiative.org $>$.

; SAUVÉ, Pierre. Services. In: CHAUFFOUR, Jean-Pierre; MAUR, JeanChristophe (ed.). Preferential Trade Agreement Policies for Development: A Handbook. Washington: Banco Mundial, 2011, p. 235-274. 
MAVROIDIS, Petros C. Regulatory Cooperation: Lessons from the WTO and the World Trade Regime. E15 Task Force on Regulatory Systems Coherence - Policy Options Paper. E15Initiative. Geneva: International Centre for Trade and Sustainable Development (ICTSD) and World Economic Forum, 2016.

MELENDÉZ-ORTIZ, Ricardo. Mega-regionals: What Is Going on? In: Mega-regional Trade Agreements Game-Changers or Costly Distractions for the World Trading System? World Economic Forum, 2014.

MESSERLIN, PATRICK. TTIP: THE SERVICES DIMENSION. In: Rule-Makers or RuleTakers? Exploring the Transatlantic Trade and Investment Partnership.Edited by Daniel S. Hamilton \& jácques Pelkmans, 2015. Published by Rowman \& Littlefield International, Ltd. Unit A, Whitacre Mews, 26-34 Stannary Street, London SE11 4AB. Disponível em: <https://www.ceps.eu/system/files/TTIP.pdf>. Acesso em: 13 out. 2017.

OLIVEIRA, Amâncio Jorge de (coord). Serviços in: JANK, Marcos S. e THORTENSEN, Vera (coords.). O Brasil e os grandes temas do comércio internacional. São Paulo: Lex Editora; Aduaneiras, 2005, p. 117- 154.

ORFORD, Anne. Theorizing Free Trade. In: ORFORD, Anne e HOFMANN, Florian (ed.). The Oxford Handbook of the Theory of International Law. Oxford, United Kingdom: Oxford University Press, 2016.

ORGANISATION FOR ECONOMIC CO-OPERATION AND DEVELOPMENT (OECD). International Regulatory Co-operation: Addressing Global Challenges. OECD Publishing, 2013. Disponível em: < http://dx.doi.org/10.1787/9789264200463-en>.

PRADO, Mariana Mota e BERTRAND, Vladimir. Regulatory Cooperation on Latin

America: The Case of Mercosur. Law and Contemporary Problems. Vol. 78: 205, p. 205 230 .

PUPO, Rodrigo. Introdução ao Acordo Geral sobre Comércio de Serviços - GATS. In: CELli JR, U. (Org). Comércio de Serviços na OMC, Curitiba, Brasil, Juruá, $1^{\text {a }}$ edição: 2005.

RENTZHOG, Magnus e ANÉR, Emilie. The New Services Era - Is GATS up to the Task? E15Initiative. Geneva: International Centre for Trade and Sustainable Development (ICTSD) and World Economic Forum, 2014. <www.e15initiative.org/>. 
RORIZ, João Henrique Ribeiro. Propriedade intelectual, serviços e investimentos: panorama de regulação de acordos de comércio celebrados pela União Europeia, Estados Unidos, China e Índia. Texto de Discussão n ${ }^{\circ}$ 1801. Pesquisa PNPD/IPEA 105/2010. IPEA: Brasília, 2012. Disponível em:

$<$ http://www.ipea.gov.br/portal/index.php?option=com_content\&view=article\&id=16577> . Acesso em: 25 jun. 2017.

ROY, Martin; MARCHETTI, Juan e LIM, Hoe. Services liberalization in the new generation of preferential trade agreements: how much further than the GATS? In: ESTEVADEORDAL, Antoni; SUOMINEN, Kati and THE, Robert. Regional rules in the Global trade system. New York: Cambridge university press, 2009.p. 316 - 364.

SÁEZ, Sebastian. Trade in Services Negotiations: A Guide for Developing Countries. Estados Unidos: International Bank for Reconstruction and Development/The World Bank.

SANCHEZ BADIN, Michelle Ratton. Compromissos assumidos por grandes e médias economias em acordos preferenciais de comércio: o contraponto entre União Europeia e Estados Unidos e China e Índia. Texto de Discussão $\mathrm{n}^{0}$ 1700. Pesquisa PNPD/IPEA 105/2010. IPEA: Brasília, 2012. Disponível em:

$<$ http://www.ipea.gov.br/portal/index.php?option=com_content\&view $=$ article\&id $=15123>$ . Acesso em: 25 jun. 2017.

SAYEG, Fernanda Manzano. Regulação doméstica e o GATS. In: CELLI JR., Umberto e SAYEG, Fernanda Manzano. Comércio de Serviços, OMC e Desenvolvimento. São Paulo: IDCID, 2008a.

. As negociações sobre regulação doméstica na OMC: estágio atual, provável forma e conteúdo do acordo e suas possíveis consequências para o Brasil e para os demais PEDs. In: CELLI JR., Umberto e SAYEG, Fernanda Manzano. Comércio de Serviços, OMC e Desenvolvimento. São Paulo: IDCID, 2008 b.

O Tratamento de questões relacionadas a serviços nos acordos regionais de comércio: uma análise dos modelos adotados por Estados Unidos, União Europeia e China com vistas ao desenvolvimento de um modelo mais adequado e desejável para o Mercosul. 2014. Tese (Doutorado em Direito) - Faculdade de Direito da USP.

SHAFFER, Gregory. How the World Trade Organization shapes regulatory governance. Regulation \&Governance, 2015, vol. 9, p. 1-15.

STEPHENSON, Sherry. Global Value Chains: The New Reality of International Trade. E15 Initiative. Geneva: International Centre for Trade and Sustainable Development (ICTSD) and World Economic Forum, 2015. Disponível em: <www.e15initiative.org>. 
Como o TiSA pode afetar os PEDs, inclusive o Brasil.

Disponível em: $<$ https://www.ictsd.org/bridges-news/pontes/news/como-o-tisa-pode-afetaros-pa\%C3\%ADses-em-desenvolvimento-inclusive-o-brasil>. Acesso em: 14 out. 2017.

SUOMINEN, Kati. 2016. Enhancing Coherence and Inclusiveness in the Global Trading System in the Era of Regionalism. E15 Expert Group on Regional Trade Agreements and Plurilateral Approaches - Policy Options Paper. E15Initiative. Geneva: International Centre for Trade and Sustainable Development (ICTSD) and World Economic Forum.

THORSTENSEN, Vera; WEISSINGER, Reinhard; e SUN, Xinhua. Private Standards: Implications for Trade, Development and Governance. E15Initiative. Geneva: International Centre for Trade and Sustainable Development (ICTSD) and World Economic Forum, 2015.

THORSTENSEN, Vera e KOTZIAS, Fernanda. Integração Regulatória: Uma proposta de Coerência, Convergência e Cooperação para a modernização do Mercosul. Boletim de Economia e Política Internacional (BEPI) n. 20, Maio/Ago. 2015, p. 21-29

Barreiras Regulatórias: um novo desafio para a governança da OMC. Centro de Estudos do Comércio Global e Investimentos. Disponível em: $<$ https://bibliotecadigital.fgv.br/dspace/bitstream/handle/10438/16369/OMC\%20e\%20Gov ernan $\% \mathrm{C} 3 \% \mathrm{~A} 7 \mathrm{a} \% 20$ Regulat $\% \mathrm{C} 3 \% \mathrm{~B} 3$ ria.pdf? sequence $=1 \&$ isAllowed $=\mathrm{y}>$. Acesso em: 07 maio 2016.

THORSTENSEN, Vera; MESQUITA, Alebe. Comércio de Serviços e Serviços Financeiros. In: Vera Thorstensen e Thiago Nogueira (Coord.). O Tratado da Parceria Transpacífico (TPP): impactos do novo marco regulatório para o Brasil. Disponível em: < http://ccgi.fgv.br/en/publications>. Acesso em: 09 out.2017. (P.197 - 238.)

THORSTENSEN, Vera e BADIN, Michelle (Coord.). Coerência e Convergência regulatória No Comércio Exterior: O Caso Do Brasil Frente A União Europeia E Estados Unidos Com Ênfase Na Experiência Do Reino Unido: Sínteses e Conclusões. Fevereiro, 2017. Disponível em: <http://ccgi.fgv.br/en/publications>. Acesso em: 02 nov. 2017.

THE NATIONAL BOARD OF TRADE. Global Value Chains and Services: An Introduction. February, 2013.

VAN TONGEREN, Frank; BASTIEN, Véronique, e VON LAMPE, Martin. International Regulatory Cooperation, a Trade-Facilitating Mechanism. E15Initiative. Geneva: International Centre for Trade and Sustainable Development (ICTSD) and World Economic Forum, 2015. 
WIJKSTROM, Erik. The Third Pillar: Behind the Scenes, WTO Committee Work Delivers. E15Initiative. Geneva: International Centre for Trade and Sustainable Development (ICTSD) and World Economic Forum, 2015.

WINSLETT, Gary. How regulations became the crux of trade politics. Journal of world trade, 2016, Vol. 50, No. 1. pp. 47-70.

WOLFE, Robert. How Can We Know (More) About the Trade Effects of Regulation? E15Initiative. Geneva: International Centre for Trade and Sustainable Development (ICTSD) and World Economic Forum, 2015.

WORLD TRADE ORGANIZATION (WTO). World Trade Report, 2012. Trade and public policies: A closer look at non-tariff measures in the 21 st century.

SHAFFER, Gregory. International Law and Global Public Goods in a Legal Pluralist World. The European Journal of International Law. Vol. 23 no. 3, p. $669-693$.

US CHAMBER OF COMMERCE. Regulatory Coherence \& Cooperation in the Transatlantic Trade and Investment Partnership (TTIP). Disponível em: $<$ https://www.uschamber.com/sites/default/files/regulatory_coherence_regulatory_coopera tion_-chamber_ttip_paper-final_2.pdf>. Acesso em: 2 nov. 2017.

Documentos:

WTO. General Agreement on Trade in Services. Disponível em:

$<$ https://www.wto.org/english/docs_e/legal_e/26-gats.pdf $>$. Acesso em: 08 maio 2016.

Transpacific Partnership Agreement. Disponível em: $<$ https://ustr.gov/tradeagreements/free-trade-agreements/trans-pacific-partnership/tpp-full-text $>$. Acesso em: 08 maio 2016.

European Comission. Regulatory cooperation in TTIP: An introduction to the EU's revised proposal. 21 de março de 2016. Disponível em: $<$ http://trade.ec.europa.eu/doclib/press/index.cfm?id=1477>. Acesso em:16 mar. 2016.

Regulatory cooperation in TTIP: The benefits. 21 de março de 2016. Disponível em: <http://trade.ec.europa.eu/doclib/press/index.cfm?id=1477>. Acesso em: 16 mar. 2016. 
. TTIP- EU proposal for Chapter: Regulatory Cooperation. Disponível em: $<$ http://trade.ec.europa.eu/doclib/press/index.cfm?id=1477>. Acesso em: 16 mar. 2016.

Good Regulatory Practices (GRPs) in TTIP: An introduction to the EU's revised proposal. Disponível em: $<$ http://trade.ec.europa.eu/doclib/press/index.cfm?id=1477>. Acesso em 16 mar. 2016.

. TTIP- EU proposal for Chapter: Good Regulatory Practices. Disponível em: $<$ http://trade.ec.europa.eu/doclib/press/index.cfm?id=1477>. Acesso em: 16 mar. 2016.

Transatlantic Trade and Investment Partnership. Trade in Services, Investment and E-commerce. Disponível em: $<$ http://trade.ec.europa.eu/doclib/press/index.cfm?id=1230>. Acesso em: 19 set. 2017.

. Services in the TTIP: Helping Europe's services firms tap the US Market. Disponível em: <http://trade.ec.europa.eu/doclib/press/index.cfm?id=1230>. Acesso em: 19 set. 2017.

Publication of the EU proposal on services, investment and ecommerce for the Transatlantic Trade and Investment Partnership. 31 de julho de 2015. Disponível em: < http://trade.ec.europa.eu/doclib/press/index.cfm?id=1230>. Acesso em: 19 set. 2017.

TTIP and Regulation: an Overview. The European Commission. 10 de fevereiro de 2015, p. 17. Disponível em: < http://trade.ec.europa.eu/doclib/docs/2015/february/tradoc_153121.pdf $>$. Acesso em: 19 set. 2017.

. Trade in Services Agreement (Tisa) Factsheet. Disponível em: < http://trade.ec.europa.eu/doclib/docs/2016/september/tradoc_154971.doc.pdf $>$. Acesso em: 14 out. 2017.

TiSA - Trade in Services Agreement. Disponível em: $<$ https://wikileaks.org/tisa/document/20160621_TiSA_Core-Text/>. Acesso em: 14 out. 2017.

TISA - Annex on Domestic Regulation. Disponível em: $<$ https://wikileaks.org/tisa/document/20151010_Annex-on-Domestic-Regulation/>. Acesso em: 14 out. 2017. Acesso em 24 out. 2017. 
MDIC - Ministério da Indústria, Comércio Exterior e Serviços. Perfis dos negócios bilaterais. MDIC, 2016b. Disponível em: <http://www.mdic.gov.br/index.php/comercioservicos/estatisticas-do-comercio-exterior-de-servicos/2555-estatisticas-do-comercioexterior-de-servicos-2016>. Acesso em 24 out. 2017.

Panorama do Comércio Internacional: Serviços 2016. MDIC, 2016. Disponível em: <http://www.mdic.gov.br/index.php/comercioservicos/estatisticas-do-comercio-exterior-de-servicos/2555-estatisticas-do-comercioexterior-de-servicos-2016>. Acesso em 24 out. 2017.

Registro de presença Comercial. MDIC: 2016a. Disponível em: <http://www.mdic.gov.br/index.php/comercio-servicos/estatisticas-docomercio-exterior-de-servicos/2555-estatisticas-do-comercio-exterior-de-servicos-2016 >. Acesso em 24 out. 2017. 


\section{ANEXO I}

TABELA DE ACORDOS DO BRASIL ANALISADOS PARA MAPEAMENTO DOS DISPOSITIVOS DE COERÊNCIA REGULATÓRIA E COMÉRCIO DE SERVIÇOS

\begin{tabular}{|c|c|c|}
\hline Acordo & $\begin{array}{c}\text { Data de } \\
\text { Assinatura }\end{array}$ & Entrada em vigor \\
\hline $\begin{array}{l}\text { Acordo de Ampliação Econômico-Comercial } \\
\text { Brasil - Peru }\end{array}$ & 29.04 .2016 & Sem vigência \\
\hline $\begin{array}{l}\text { Preferência Tarifária Regional entre países } \\
\text { da ALADI (PTR-04) e protocolos adicionais }\end{array}$ & 27.04 .1984 & 28.12 .1984 \\
\hline $\begin{array}{l}\text { Acordo de cooperação científica e tecnológica } \\
\left(\text { AR.CYT } N^{0} \text { 6) }\right.\end{array}$ & 19.10 .1993 & 03.05 .1994 \\
\hline $\begin{array}{l}\text { Acordo de Sementes entre países da ALADI } \\
\left(\text { AAP.AG } N^{\circ} \text { 2) }\right.\end{array}$ & 22.11 .1991 & 19.03 .1993 \\
\hline $\begin{array}{l}\text { Acordo de Bens Culturais entre países da } \\
\text { ALADI (AR.CEYC No 7) }\end{array}$ & 27.10 .1988 & 08.02 .1989 \\
\hline $\begin{array}{l}\text { Convênio Constitutivo do Conselho } \\
\text { Agropecuário do Sul (CAS) (AAP.AG No 3) }\end{array}$ & 08.08 .2006 & 20.12.2010 \\
\hline AAP.PC No 2 Bolívia Brasil & 17.08 .1992 & 11.11 .1992 \\
\hline $\begin{array}{l}\text { AAP.PC No } 5 \text { Argentina Brasil Paraguai } \\
\text { Uruguai }\end{array}$ & 18.05.1994 & 14.10.1994 \\
\hline $\begin{array}{l}\text { AAP.PC No } 7 \text { Argentina Brasil Paraguai } \\
\text { Uruguai }\end{array}$ & 30.12 .1994 & 25.01 .1996 \\
\hline $\begin{array}{l}\text { AAP.PC No } 8 \text { Argentina Brasil Paraguai } \\
\text { Uruguai }\end{array}$ & 30.12 .1994 & 19.07.1995 \\
\hline $\begin{array}{l}\text { AAP.PC No } 11 \text { Argentina Bolívia Brasil Chile } \\
\text { Colômbia Cuba Equador México Paraguai } \\
\text { Peru Uruguai Venezuela }\end{array}$ & 08.12 .1997 & 30.07 .1998 \\
\hline $\begin{array}{l}\text { AAP.PC No } 19 \text { Argentina Brasil Chile } \\
\text { Colômbia Equador Paraguai Uruguai } \\
\text { Venezuela }\end{array}$ & 09.12 .2005 & 26.01 .2010 \\
\hline Brasil - Uruguai (ACE-02) & 20.12 .1982 & 20.06 .1983 \\
\hline Brasil-Argentina (ACE-14) & 20.12 .1990 & 15.03 .1991 \\
\hline Mercosul - Chile (ACE-35) & 25.06 .1996 & 12.09 .1996 \\
\hline Mercosul - Bolívia (ACE-36) & 17.12 .1996 & 28.05 .1997 \\
\hline Brasil - México (ACE-53) & 03.07 .2002 & 02.05 .2003 \\
\hline Mercosul - México (ACE-54) & 05.07 .2002 & 05.01 .2006 \\
\hline Automotivo Mercosul - México (ACE-55) & 27.09 .2002 & 15.01 .2003 \\
\hline Mercosul - Peru (ACE-58) & 30.11 .2005 & 29.12 .2005 \\
\hline $\begin{array}{l}\text { Mercosul - Colômbia, Equador e Venezuela } \\
\text { (ACE-59) }\end{array}$ & 18.10 .2004 & $\begin{array}{l}01.04 .2005 * * \\
01.02 .2005 * * * \\
\end{array}$ \\
\hline $\begin{array}{l}\text { Brasil/Guiana/São Cristóvão e Névis } \\
\text { (AAP.A25TM 38) }\end{array}$ & 27.06.2001 & 29.10 .2001 \\
\hline Brasil - Suriname (AAP.A25TM No 41) & 21.04 .2005 & 26.07 .2006 \\
\hline
\end{tabular}




\begin{tabular}{|c|c|c|}
\hline Acordo & $\begin{array}{c}\text { Data de } \\
\text { Assinatura } \\
\end{array}$ & Entrada em vigor \\
\hline Brasil - Venezuela (ACE-69) & 26.12 .2012 & 14.10 .2014 \\
\hline Mercosul - Cuba (ACE-62) & 21.07 .2006 & $02.07 .2007^{*}$ \\
\hline Mercosul/Índia & 25.01 .2004 & 01.06 .2009 \\
\hline Mercosul/Israel & 18.12 .2007 & 28.04 .2010 \\
\hline Mercosul/SACU & 15.12 .2008 & 01.04 .2016 \\
\hline Mercosul/Egito & 02.08 .2010 & 07.12 .2017 \\
\hline Mercosul/Palestina & 20.12 .2011 & Sem vigência \\
\hline Mercosul (Decisão CMC 13/97) & 23.07 .1998 & 07.12 .2005 \\
\hline Mercosul (ACE -18) & 29.11 .1991 & 27.05 .1992 \\
\hline $\begin{array}{l}\text { AAP.A14TM No } 3 \text { Argentina Bolívia Brasil } \\
\text { Chile Paraguai Peru Uruguai }\end{array}$ & 01.01 .1990 & 21.11.1990 \\
\hline $\begin{array}{l}\text { AAP.A14TM No } 4 \text { Argentina Bolívia Brasil } \\
\text { Chile Colômbia Equador Paraguai Peru } \\
\text { Uruguai Venezuela }\end{array}$ & 30.08 .1990 & 15.06 .1991 \\
\hline $\begin{array}{l}\text { AAP.A14TM N } 5 \text { Argentina Bolívia Brasil } \\
\text { Paraguai Uruguai }\end{array}$ & 26.06 .1992 & 16.12.1994 \\
\hline AAP.A14TM No 6 Argentina Brasil Uruguai & 27.06 .1992 & 15.09 .1992 \\
\hline AAP.A14TM No 7 Brasil Uruguai & 30.12 .1992 & 29.04 .1993 \\
\hline $\begin{array}{l}\text { AAP.A14TM No } 8 \text { Argentina Bolívia Brasil } \\
\text { Chile Paraguai Peru Uruguai }\end{array}$ & 29.09.1992 & 04.08 .1993 \\
\hline $\begin{array}{l}\text { AAP.A14TM No } 9 \text { Argentina Brasil Paraguai } \\
\text { Uruguai }\end{array}$ & 22.05 .1995 & 02.08 .1995 \\
\hline $\begin{array}{l}\text { AAP.A14TM No } 10 \text { Bolívia Brasil Chile } \\
\text { Paraguai Peru Uruguai }\end{array}$ & 16.08 .1995 & 16.04 .1996 \\
\hline $\begin{array}{l}\text { AAP.A14TM No } 12 \text { Argentina Brasil } \\
\text { Paraguai Uruguai (Mercosul) Guatemala } \\
\text { Honduras El Salvador Nicarágua Costa Rica } \\
\text { (MCCA) }\end{array}$ & 18.04.1998 & 10.12 .1998 \\
\hline AAP.A14TM No 15 Brasil Venezuela & 04.07 .1995 & Sem informação \\
\hline $\begin{array}{l}\text { AAP.A14TM No } 17 \text { Argentina Brasil } \\
\text { Paraguai Uruguai }\end{array}$ & 04.07 .1995 & 09.11 .2011 \\
\hline Mercosul - Colômbia (ACE - 72) & 21.07 .2017 & 07.12 .2017 \\
\hline
\end{tabular}

*Para o Brasil

** Entre Brasil e Equador

*** Entre Brasil e Colombia e Venezuela

Fontes: Elaboração própria com dados do MRE, MDIC e ALADI.

$<$ http://www.mre.gov.py/tratados/public_web/ConsultaMercosur.aspx $>$.

$<$ http://www.mdic.gov.br/comercio-exterior/negociacoes-internacionais/796-negociacoesinternacionais-2>.

$<$ http://www.aladi.org/sitioAladi/acuerdosP.html $>$. 


\section{ANEXO II}

\section{TABELA COMPARATIVA DOS DISPOSITIVOS DE REGULAMENTAÇÃO DOMÉSTICA NOS COMPROMISSOS ASSUMIDOS PELO BRASIL COM OUTROS PARCEIROS COMERCIAIS}

\begin{tabular}{|c|c|c|c|}
\hline \multicolumn{4}{|c|}{ Dispositivo de Regulamentação Doméstica nos Acordos do Brasil } \\
\hline GATS* & & $\begin{array}{l}\text { Acordo Mercosul - } \\
\text { Chile (ACE - 35) }\end{array}$ & Acordo Brasil - Peru \\
\hline $\begin{array}{l}\text { Artigo VI } \\
\text { Legislação Nacional } \\
\text { 1. Nos setores em } \\
\text { que compromissos } \\
\text { específicos sejam } \\
\text { assumidos, cada } \\
\text { Membro velará para } \\
\text { que todas as medidas } \\
\text { de aplicação geral } \\
\text { que afetem o } \\
\text { comércio de serviços } \\
\text { sejam administradas } \\
\text { de maneira razoável, } \\
\text { objetiva e imparcial. } \\
\text { 2. a) Cada Membro } \\
\text { manterá ou instituirá } \\
\text { tão logo seja factível } \\
\text { tribunais judiciais, } \\
\text { arbitrais ou } \\
\text { administrativos ou } \\
\text { procedimentos que } \\
\text { permitam, após } \\
\text { solicitação de um } \\
\text { prestador de serviços } \\
\text { afetado, a pronta } \\
\text { revisão das decisões } \\
\text { administrativas que } \\
\text { afetem o comércio } \\
\text { de serviços e, } \\
\text { quando for } \\
\text { justificado, a } \\
\text { aplicação de recursos } \\
\text { apropriados. Quando } \\
\text { tais procedimentos } \\
\text { não sejam } \\
\text { independentes do } \\
\text { órgão encarregado } \\
\text { da decisão } \\
\text { administrativa, o } \\
\text { Membro velará para } \\
\text { que o recurso seja }\end{array}$ & $\begin{array}{l}\text { Artigo X } \\
\text { Regulamentação } \\
\text { nacional } \\
\text { 1. Cada Estado } \\
\text { Parte velará para } \\
\text { que todas as } \\
\text { medidas de } \\
\text { aplicação geral } \\
\text { que afetem o } \\
\text { comércio de } \\
\text { serviços sejam } \\
\text { administradas de } \\
\text { maneira } \\
\text { razoável, } \\
\text { objetiva e } \\
\text { imparcial. } \\
\text { 2. Cada Estado } \\
\text { Parte manterá ou } \\
\text { estabelecerá } \\
\text { tribunais ou } \\
\text { procedimentos } \\
\text { judiciais, } \\
\text { arbitrais ou } \\
\text { administrativos } \\
\text { que permitam, a } \\
\text { pedido de um } \\
\text { prestador de } \\
\text { serviços afetado, } \\
\text { a pronta revisão } \\
\text { das decisões } \\
\text { administrativas } \\
\text { que afetem o } \\
\text { comércio de } \\
\text { serviços e, } \\
\text { quando for } \\
\text { justificado, a } \\
\text { aplicação de } \\
\text { soluçôes } \\
\text { apropriadas. } \\
\text { Quando tais } \\
\text { procedimentos } \\
\end{array}$ & $\begin{array}{l}\text { Artigo VII. } \\
\text { Regulamentação } \\
\text { Doméstica } \\
\text { 1. Nada no presente } \\
\text { Protocolo será } \\
\text { interpretado no } \\
\text { sentido de impedir o } \\
\text { direito de cada Parte } \\
\text { Signatária, de acordo } \\
\text { com o estabelecido no } \\
\text { Artigo V (Listas de } \\
\text { Compromissos } \\
\text { Específicos), de } \\
\text { regulamentar e de } \\
\text { introduzir novas } \\
\text { regulamentações } \\
\text { dentro de seus } \\
\text { próprios territórios } \\
\text { para atingir seus } \\
\text { objetivos de política } \\
\text { nacional. } \\
\text { 2. Nos setores em que } \\
\text { compromissos } \\
\text { específicos sejam } \\
\text { assumidos, cada Parte } \\
\text { Signatária velará para } \\
\text { que todas as medidas } \\
\text { de aplicação geral que } \\
\text { afetem o comércio de } \\
\text { serviços sejam } \\
\text { administradas de } \\
\text { maneira razoável, } \\
\text { objetiva e imparcial. } \\
\text { 3. Cada Parte } \\
\text { Signatária velará, } \\
\text { igualmente, para que, } \\
\text { nos setores nos quais } \\
\text { compromissos } \\
\text { específicos sejam } \\
\text { assumidos, as } \\
\text { medidas relativas aos }\end{array}$ & $\begin{array}{l}\text { Artigo 3.7: } \\
\text { Regulamentação } \\
\text { Doméstica } \\
\text { 1. Cada Parte } \\
\text { assegurará que todas as } \\
\text { medidas de aplicação } \\
\text { geral que afetem o } \\
\text { comércio de serviços } \\
\text { sejam administradas de } \\
\text { maneira razoável, } \\
\text { objetiva e imparcial. } \\
\text { 2. Reconhecendo o } \\
\text { direito de regular e } \\
\text { introduzir novos } \\
\text { regulamentos sobre a } \\
\text { prestação de serviços } \\
\text { para satisfazer } \\
\text { objetivos de políticas } \\
\text { públicas e com o fim de } \\
\text { assegurar que as } \\
\text { medidas relativas a } \\
\text { requisitos e } \\
\text { procedimentos em } \\
\text { matéria de qualificação, } \\
\text { normas técnicas e } \\
\text { licenciamento: } \\
\text { a) não constituam } \\
\text { barreiras desnecessárias } \\
\text { ao comércio de } \\
\text { serviços, cada Parte } \\
\text { assegurará, nos setores } \\
\text { em que tenha assumido } \\
\text { compromissos } \\
\text { específicos em } \\
\text { conformidade com o } \\
\text { GATS, que tais } \\
\text { medidas: } \\
\text { (i) sejam baseadas em } \\
\text { critérios objetivos e } \\
\text { transparentes, como a } \\
\text { competência e a }\end{array}$ \\
\hline
\end{tabular}




\begin{tabular}{|c|c|c|c|}
\hline \multicolumn{4}{|c|}{ Dispositivo de Regulamentação Doméstica nos Acordos do Brasil } \\
\hline GATS* & & $\begin{array}{l}\text { Acordo Mercosul - } \\
\text { Chile (ACE - 35) }\end{array}$ & Acordo Brasil - Peru \\
\hline $\begin{array}{l}\text { objetivo e imparcial. } \\
\text { b) As disposições da } \\
\text { alínea (a) não devem } \\
\text { ser interpretadas no } \\
\text { sentido de obrigar } \\
\text { qualquer Membro a } \\
\text { instituir tais tribunais } \\
\text { ou procedimentos } \\
\text { quando isto for } \\
\text { incompatível com } \\
\text { sua estrutura } \\
\text { constitucional ou } \\
\text { com seu sistema } \\
\text { jurídico. } \\
\text { 3. Quando for } \\
\text { exigida autorização } \\
\text { para a prestação de } \\
\text { um serviço sobre o } \\
\text { qual haja sido } \\
\text { assumido um } \\
\text { compromisso } \\
\text { específico, as } \\
\text { autoridades } \\
\text { competentes do } \\
\text { Membro de que se } \\
\text { trate deverão, dentro } \\
\text { de um período de } \\
\text { tempo razoável após } \\
\text { a submissão de uma } \\
\text { inscrição, que se } \\
\text { considere completa } \\
\text { segundo as leis e } \\
\text { regulamentos } \\
\text { nacionais } \\
\text { pertinentes, informar } \\
\text { o pretendente da } \\
\text { decisão concernente } \\
\text { à inscrição. Após } \\
\text { solicitação do } \\
\text { pretendente, as } \\
\text { autoridades } \\
\text { competentes } \\
\text { fornecerão, sem } \\
\text { demora indevida, } \\
\text { informação sobre a } \\
\text { situação da } \\
\text { inscrição. }\end{array}$ & $\begin{array}{l}\text { não forem } \\
\text { independentes do } \\
\text { órgão } \\
\text { encarregado da } \\
\text { decisão } \\
\text { administrativa de } \\
\text { que se tratar, o } \\
\text { Estado Parte } \\
\text { velará para que } \\
\text { permitam de fato } \\
\text { uma revisão } \\
\text { objetiva e } \\
\text { imparcial. } \\
\text { As disposições } \\
\text { desse item não } \\
\text { serão } \\
\text { interpretadas no } \\
\text { sentido de impor } \\
\text { a qualquer } \\
\text { Estado Parte a } \\
\text { obrigação de } \\
\text { estabelecer esses } \\
\text { tribunais ou } \\
\text { procedimentos } \\
\text { quando isso for } \\
\text { incompatível } \\
\text { com a sua } \\
\text { estrutura } \\
\text { constitucional ou } \\
\text { com a natureza } \\
\text { do seu sistema } \\
\text { jurídico. } \\
\text { 3. Quando se } \\
\text { exigir licença, } \\
\text { matrícula, } \\
\text { certificado ou } \\
\text { outro tipo de } \\
\text { autorização para } \\
\text { a prestação de } \\
\text { um serviço, as } \\
\text { autoridades } \\
\text { competentes do } \\
\text { Estado Parte de } \\
\text { que se tratar, } \\
\text { num prazo } \\
\text { prudencial a } \\
\text { partir da }\end{array}$ & $\begin{array}{l}\text { requisitos e } \\
\text { procedimentos em } \\
\text { matéria de } \\
\text { qualificação, padrões } \\
\text { técnicos e requisitos } \\
\text { em matéria de } \\
\text { licenças sejam } \\
\text { baseados em critérios } \\
\text { objetivos e } \\
\text { transparentes e não } \\
\text { constituam restrição } \\
\text { encoberta à prestação } \\
\text { de um serviço. } \\
\text { 4. As Partes } \\
\text { Contratantes } \\
\text { considerarão o } \\
\text { desenvolvimento de } \\
\text { futuras disciplinas } \\
\text { sobre regulamentação } \\
\text { doméstica no âmbito } \\
\text { do presente Protocolo, } \\
\text { que levarão em conta } \\
\text { os resultados das } \\
\text { negociações sobre o } \\
\text { tema na Organização } \\
\text { Mundial do } \\
\text { Comércio. } \\
\text { 5. Quando for exigida } \\
\text { autorização para a } \\
\text { prestação de um } \\
\text { serviço em relação ao } \\
\text { qual tenha sido } \\
\text { assumido um } \\
\text { compromisso } \\
\text { específico, as } \\
\text { autoridades } \\
\text { competentes da } \\
\text { respectiva Parte } \\
\text { Signatária, dentro de } \\
\text { um prazo razoável a } \\
\text { partir da apresentação } \\
\text { de uma solicitação } \\
\text { que se considere } \\
\text { completa segundo as } \\
\text { leis e os regulamentos } \\
\text { nacionais pertinentes, } \\
\text { informarão o }\end{array}$ & $\begin{array}{l}\text { habilidade para prestar } \\
\text { o serviço; } \\
\text { (ii) não sejam mais } \\
\text { gravosas que o } \\
\text { necessário para } \\
\text { assegurar a qualidade } \\
\text { de serviço; e } \\
\text { (iii) no caso de } \\
\text { procedimentos em } \\
\text { matéria de } \\
\text { licenciamento, não } \\
\text { constituam em si } \\
\text { mesmas uma restrição à } \\
\text { prestação de serviço. } \\
\text { b) não constituam } \\
\text { restrições encobertas ao } \\
\text { comércio de serviços, } \\
\text { cada Parte assegurará, } \\
\text { nos setores em que não } \\
\text { tenha assumido } \\
\text { compromissos } \\
\text { específicos em } \\
\text { conformidade com o } \\
\text { GATS, que tais } \\
\text { medidas: } \\
\text { (i) sejam baseadas em } \\
\text { critérios objetivos e } \\
\text { transparentes, como a } \\
\text { competência e a } \\
\text { habilidade para prestar } \\
\text { o serviço; } \\
\text { (ii) não constituam uma } \\
\text { discriminação arbitrária } \\
\text { ou injustificável entre } \\
\text { prestadores de serviços; } \\
\text { e } \\
\text { (iii) no caso de } \\
\text { procedimentos em } \\
\text { matéria de } \\
\text { licenciamento, não } \\
\text { constituam em si } \\
\text { mesmas uma restrição à } \\
\text { prestação de serviço. } \\
\text { 3. Caso uma Parte exija } \\
\text { autorização para a } \\
\text { prestação de um } \\
\text { servico, assegurará que }\end{array}$ \\
\hline
\end{tabular}




\begin{tabular}{|c|c|c|c|}
\hline \multicolumn{4}{|c|}{ Dispositivo de Regulamentação Doméstica nos Acordos do Brasil } \\
\hline GATS* & \begin{tabular}{|l|} 
Protocolo de \\
Montevidéu
\end{tabular} & $\begin{array}{l}\text { Acordo Mercosul - } \\
\text { Chile (ACE - 35) }\end{array}$ & Acordo Brasil - Peru \\
\hline $\begin{array}{l}\text { 4. Com o objetivo de } \\
\text { assegurar que } \\
\text { medidas relativas a } \\
\text { requisitos e } \\
\text { procedimentos em } \\
\text { matéria de } \\
\text { qualificação, de } \\
\text { normas técnicas e } \\
\text { requisitos em } \\
\text { matéria de licenças } \\
\text { não constituam } \\
\text { obstáculos } \\
\text { desnecessários ao } \\
\text { comércio de } \\
\text { serviços, o Conselho } \\
\text { para o Comércio de } \\
\text { Serviços, por meio } \\
\text { dos órgãos } \\
\text { apropriados que } \\
\text { venha a instituir, } \\
\text { estabelecerá as } \\
\text { disciplinas } \\
\text { necessárias. Tais } \\
\text { disciplinas } \\
\text { objetivarão assegurar } \\
\text { que tais requisitos, } \\
\text { inter alia: } \\
\text { a) sejam baseados } \\
\text { em critérios } \\
\text { objetivos e } \\
\text { transparentes, tais } \\
\text { como a competência } \\
\text { e a habilidade para } \\
\text { prestar o serviço; } \\
\text { b) não sejam mais } \\
\text { gravosas que o } \\
\text { necessário para } \\
\text { assegurar a } \\
\text { qualidade do serviço; } \\
\text { c) no caso dos } \\
\text { procedimentos em } \\
\text { matéria de licença, } \\
\text { não constituam em si } \\
\text { mesmos uma } \\
\text { restrição para a } \\
\text { prestação do serviço. } \\
\text { 5. a) Nos setores nos }\end{array}$ & $\begin{array}{l}\text { apresentação de } \\
\text { uma petição: } \\
\text { i) Quando a } \\
\text { petição estiver } \\
\text { completa, } \\
\text { deliberarão sobre } \\
\text { a mesma } \\
\text { informando o } \\
\text { interessado; ou } \\
\text { ii) Quando a } \\
\text { petição não } \\
\text { estiver completa, } \\
\text { informarão o } \\
\text { interessado sem } \\
\text { atrasos } \\
\text { desnecessários } \\
\text { sobre o estado da } \\
\text { petição, assim } \\
\text { como sobre } \\
\text { informações } \\
\text { adicionais que } \\
\text { forem exigidas } \\
\text { de acordo com a } \\
\text { lei do Estado } \\
\text { Parte. } \\
\text { 4. Com o } \\
\text { objetivo de } \\
\text { assegurar que as } \\
\text { medidas relativas } \\
\text { às normas } \\
\text { técnicas, } \\
\text { requisitos e } \\
\text { procedimentos } \\
\text { em matéria de } \\
\text { títulos de aptidão } \\
\text { e os requisitos } \\
\text { em matéria de } \\
\text { licenças não } \\
\text { constituam } \\
\text { obstáculos } \\
\text { desnecessários } \\
\text { ao comércio de } \\
\text { serviços, os } \\
\text { Estados Partes } \\
\text { velarão para que } \\
\text { estes requisitos e } \\
\text { procedimentos, }\end{array}$ & $\begin{array}{l}\text { solicitante da decisão } \\
\text { concernente a sua } \\
\text { solicitação. A pedido } \\
\text { do solicitante, as } \\
\text { autoridades } \\
\text { competentes da Parte } \\
\text { Signatária fornecerão, } \\
\text { sem demora } \\
\text { injustificada, } \\
\text { informação referente } \\
\text { à situação da } \\
\text { solicitação. } \\
\text { 6. As Partes } \\
\text { Contratantes } \\
\text { celebrarão, } \\
\text { periodicamente, } \\
\text { consultas com o } \\
\text { intuito de determinar } \\
\text { se é possível eliminar } \\
\text { restrições } \\
\text { remanescentes em } \\
\text { matéria de cidadania } \\
\text { ou de residência } \\
\text { permanente relativas } \\
\text { à concessão de } \\
\text { licenças ou } \\
\text { certificados de seus } \\
\text { respectivos } \\
\text { prestadores de } \\
\text { serviços. }\end{array}$ & $\begin{array}{l}\text { as autoridades } \\
\text { competentes dessa } \\
\text { Parte: } \\
\text { (a) em um prazo } \\
\text { razoável a partir da } \\
\text { apresentação de uma } \\
\text { solicitação considerada } \\
\text { completa em } \\
\text { conformidade com as } \\
\text { leis e regulamentos } \\
\text { dessa Parte, informem } \\
\text { ao requerente sobre a } \\
\text { decisão relativa ao seu } \\
\text { pedido; } \\
\text { (b) a pedido do } \\
\text { requerente, forneçam, } \\
\text { sem demora indevida, } \\
\text { informações relativas à } \\
\text { situação da solicitação; } \\
\text { (c) em conformidade } \\
\text { com as leis e } \\
\text { regulamentos daquela } \\
\text { Parte, no caso de } \\
\text { solicitação incompleta, } \\
\text { a pedido do requerente, } \\
\text { identifiquem a } \\
\text { informação adicional } \\
\text { necessária para } \\
\text { completar a solicitação } \\
\text { e proporcionem a } \\
\text { oportunidade de } \\
\text { corrigir erros ou } \\
\text { omissões menores; } \\
\text { (d) na medida do } \\
\text { praticável, estabeleçam } \\
\text { prazos indicativos para } \\
\text { o processamento de } \\
\text { uma solicitação; } \\
\text { (e) caso uma solicitação } \\
\text { seja denegada, } \\
\text { informem ao } \\
\text { requerente, na medida } \\
\text { do praticável, sobre as } \\
\text { razões da denegação, } \\
\text { seja de forma direta, } \\
\text { seja a pedido do } \\
\text { requerente; e }\end{array}$ \\
\hline
\end{tabular}




\begin{tabular}{|c|c|c|c|}
\hline \multicolumn{4}{|c|}{ Dispositivo de Regulamentação Doméstica nos Acordos do Brasil } \\
\hline GATS* & $\begin{array}{l}\text { Protocolo de } \\
\text { Montevidéu }\end{array}$ & $\begin{array}{l}\text { Acordo Mercosul - } \\
\text { Chile (ACE - 35) }\end{array}$ & Acordo Brasil - Peru \\
\hline $\begin{array}{l}\text { quais um Membro } \\
\text { tenha assumido } \\
\text { compromissos } \\
\text { específicos, até a } \\
\text { entrada em vigor das } \\
\text { disciplinas que se } \\
\text { elaborem para estes } \\
\text { setores em virtude } \\
\text { do parágrafo 4, dito } \\
\text { Membro não aplicará } \\
\text { requisitos em } \\
\text { matéria de licenças e } \\
\text { qualificações nem } \\
\text { normas técnicas que } \\
\text { anulem ou } \\
\text { prejudiquem (nullify } \\
\text { or impair) os } \\
\text { compromissos } \\
\text { específicos de modo } \\
\text { que: } \\
\text { i) não sejam } \\
\text { conformes com os } \\
\text { critérios descritos } \\
\text { nas alíneas (a), (b) e } \\
\text { (c) do parágrafo 4; e } \\
\text { ii) não poderiam } \\
\text { haver sido } \\
\text { razoavelmente } \\
\text { esperados da parte } \\
\text { deste Membro no } \\
\text { momento em que } \\
\text { assumiu os } \\
\text { compromissos } \\
\text { específicos naqueles } \\
\text { setores. } \\
\text { b) Ao se determinar } \\
\text { se um Membro } \\
\text { cumpre a obrigação } \\
\text { prevista na alínea (a) } \\
\text { do presente } \\
\text { parágrafo, serão } \\
\text { levadas em conta } \\
\text { normas } \\
\text { internacionais das } \\
\text { organizações } \\
\text { internacionais } \\
\text { competentes }\end{array}$ & $\begin{array}{l}\text { dentre outras } \\
\text { coisas: } \\
\text { i) estejam } \\
\text { baseados em } \\
\text { critérios } \\
\text { objetivos e } \\
\text { transparentes, } \\
\text { tais como a } \\
\text { competência e a } \\
\text { capacidade para } \\
\text { prestar o serviço; } \\
\text { ii) não sejam } \\
\text { mais onerosos do } \\
\text { que o necessário } \\
\text { para assegurar a } \\
\text { qualidade do } \\
\text { serviço; e } \\
\text { iii) no caso de } \\
\text { procedimentos } \\
\text { em matéria de } \\
\text { licenças, não } \\
\text { constituam em si } \\
\text { mesmos uma } \\
\text { restrição à } \\
\text { prestação do } \\
\text { serviço. } \\
5 . \text { Cada Estado } \\
\text { Parte poderá } \\
\text { estabelecer os } \\
\text { procedimentos } \\
\text { adequados para } \\
\text { verificar a } \\
\text { competência dos } \\
\text { profissionais dos } \\
\text { outros Estados } \\
\text { Partes. }\end{array}$ & & $\begin{array}{l}\text { (f) na medida do } \\
\text { praticável e em } \\
\text { conformidade com a } \\
\text { sua legislação interna, } \\
\text { aceitem cópias de } \\
\text { documentos que } \\
\text { estejam autenticados, } \\
\text { no lugar de documentos } \\
\text { originais. } \\
\text { 4. Cada Parte deverá } \\
\text { assegurar que qualquer } \\
\text { taxa cobrada pela } \\
\text { autoridade competente } \\
\text { para autorizar a } \\
\text { prestação de um serviço } \\
\text { seja razoável, } \\
\text { transparente e por si } \\
\text { mesma não restrinja a } \\
\text { prestação desse serviço. } \\
\text { Para os fins deste } \\
\text { parágrafo, "taxa" não } \\
\text { inclui pagamentos para } \\
\text { o uso dos recursos } \\
\text { naturais, pagamentos de } \\
\text { leilões, licitações ou } \\
\text { outros meios não } \\
\text { discriminatórios de } \\
\text { outorga de concessões, } \\
\text { ou contribuições } \\
\text { obrigatórias para a } \\
\text { prestação de serviço } \\
\text { universal. } \\
\text { 5. Caso os requisitos de } \\
\text { licenciamento ou } \\
\text { qualificação incluam } \\
\text { uma avaliação, cada } \\
\text { Parte procurará } \\
\text { assegurar que: } \\
\text { (a) a avaliação seja } \\
\text { programada em } \\
\text { intervalos razoáveis; e } \\
\text { (b) seja concedido } \\
\text { prazo razoável que } \\
\text { permita às pessoas } \\
\text { interessadas apresentar } \\
\text { solicitação para } \\
\text { participar da avaliação. }\end{array}$ \\
\hline
\end{tabular}




\begin{tabular}{|c|c|c|c|}
\hline \multicolumn{4}{|c|}{ Dispositivo de Regulamentação Doméstica nos Acordos do Brasil } \\
\hline GATS* & $\begin{array}{l}\text { Protocolo de } \\
\text { Montevidéu }\end{array}$ & $\begin{array}{l}\text { Acordo Mercosul - } \\
\text { Chile (ACE - 35) }\end{array}$ & Acordo Brasil - Peru \\
\hline $\begin{array}{l}\text { aplicadas por aquele } \\
\text { Membro. } \\
\text { 6. Nos setores em } \\
\text { que sejam assumidos } \\
\text { compromissos } \\
\text { concernentes a } \\
\text { serviços } \\
\text { profissionais, cada } \\
\text { Membro estabelecerá } \\
\text { procedimentos } \\
\text { adequados para } \\
\text { verificar a } \\
\text { competência dos } \\
\text { profissionais de } \\
\text { qualquer outro } \\
\text { Membro. }\end{array}$ & & & $\begin{array}{l}\text { 6. Ao se determinar se } \\
\text { uma Parte cumpre a } \\
\text { obrigação estabelecida } \\
\text { no parágrafo 2, serão } \\
\text { tomados em conta os } \\
\text { padrões internacionais } \\
\text { das organizações } \\
\text { internacionais } \\
\text { competentes aplicados } \\
\text { por essa Parte. Por } \\
\text { “organizações } \\
\text { internacionais } \\
\text { competentes”, } \\
\text { entendem-se os } \\
\text { organismos } \\
\text { internacionais dos quais } \\
\text { possam ser Membros os } \\
\text { organismos } \\
\text { competentes das Partes. } \\
\text { 7. As Partes poderão } \\
\text { celebrar consultas } \\
\text { periodicamente com o } \\
\text { objetivo de determinar } \\
\text { se é possível eliminar } \\
\text { as restrições restantes } \\
\text { em matéria de } \\
\text { nacionalidade ou } \\
\text { residência permanente } \\
\text { relativas à concessão de } \\
\text { licenças ou } \\
\text { certificações para seus } \\
\text { respectivos prestadores } \\
\text { de serviços. } \\
\text { 8. Cada Parte } \\
\text { assegurará que existam } \\
\text { procedimentos } \\
\text { apropriados para } \\
\text { verificar a competência } \\
\text { dos profissionais da } \\
\text { outra Parte. } \\
\text { 9. As Partes revisarão } \\
\text { este Artigo } \\
\text { considerando os } \\
\text { avanços nas } \\
\text { negociações que se } \\
\text { realizem ao amparo do } \\
\text { Artigo VI do GATS, }\end{array}$ \\
\hline
\end{tabular}




\begin{tabular}{|c|c|c|c|}
\hline \multicolumn{4}{|c|}{ Dispositivo de Regulamentação Doméstica nos Acordos do Brasil } \\
\hline GATS* & \begin{tabular}{|l|} 
Protocolo de \\
Montevidéu
\end{tabular} & $\begin{array}{l}\text { Acordo Mercosul - } \\
\text { Chile (ACE - 35) }\end{array}$ & Acordo Brasil - Peru \\
\hline & & & $\begin{array}{l}\text { com o objetivo de } \\
\text { integrá-los a este } \\
\text { Capítulo. } \\
\text { 10. As obrigações } \\
\text { estabelecidas nos } \\
\text { parágrafos } 2,3,4,5 \text { e } 8 \\
\text { serão aplicadas em } \\
\text { conformidade com os } \\
\text { termos, limitações e } \\
\text { condições da Lista de } \\
\text { Compromissos } \\
\text { Específicos de cada } \\
\text { Parte. } \\
11 . \text { No cumprimento } \\
\text { deste Artigo, cada Parte } \\
\text { tomará as medidas } \\
\text { razoáveis que estejam a } \\
\text { seu alcance, para } \\
\text { garantir sua } \\
\text { observância por } \\
\text { instituições não } \\
\text { governamentais } \\
\text { existentes em seu } \\
\text { território. }\end{array}$ \\
\hline
\end{tabular}

Fonte: MDIC, ALADI e Planalto.

GATS: <http://www.mdic.gov.br/arquivos/dwnl_1244492330.pdf $>$.

Acordo Mercosul-Chile:

$<$ http://www.aladi.org/nsfaladi/textacdos.nsf/f7a2d493807d9e8c032574e100640526/6ba70 a0157ba3e3e03257f79005ea54e?OpenDocument $\geq$.

Protocolo de Montevidéu: <http://www.planalto.gov.br/ccivil_03/_ato2007-

2010/2008/decreto/d6480.htm $\geq$.

Acordo Brasil-Peru: <http://www.mdic.gov.br/index.php/comércio-exterior/negociacoesinternacionais/9-assuntos/categ-comércio-exterior/1508-acordo-de-ampliacao-economicocomercial-brasil-peru-ainda-sem-vigencia $\geq$.

* Conforme Projeto Releitura: IC. Comentários sobre a Tradução Artigo VI. 2 No item (a), a melhor tradução para a palavra "remedies" seria "soluções" e não "recursos"; Artigo VI.3 No item (a), a melhor tradução para a palavra "application" seria "solicitação" e não "inscrição", embora o termo inscrição sirva para distinguir da tradução proposta para o termo "request" (solicitação). Artigo VI.5 No item (a), a melhor tradução para a palavra "impair" seria "comprometam" e não "prejudiquem", já que aquela tem um sentido mais abrangente do que esta. É claro que a alteração é menos ou mais vantajosa em função do interesse que o Membro pretende defender. Disponível em:

$<$ http://ccgi.fgv.br/sites/ccgi.fgv.br/files/file/Publicacoes/

14\%20Acordo $\% 20$ Geral $\% 20$ sobre $\% 20$ o\%20Com $\%$ C3\%A9rcio\%20de $\% 20$ Servi $\% C 3 \% A 7$ os\%20\%28GATS\% 29.pdf>. Acesso em: 21 out. 2017. 


\section{ANEXO III}

\section{TABELA COMPARATIVA DOS DISPOSITIVOS DE RECONHECIMENTO NOS COMPROMISSOS ASSUMIDOS PELO BRASIL COM OUTROS PARCEIROS COMERCIAIS}

\begin{tabular}{|c|c|c|c|}
\hline \multicolumn{4}{|c|}{ Dispositivo de Regulamentação Doméstica nos Acordos do Brasil } \\
\hline GATS* & $\begin{array}{l}\text { Protocolo de } \\
\text { Montevidéu }\end{array}$ & $\begin{array}{l}\text { Acordo Mercosul - } \\
\text { Chile (ACE - 35) }\end{array}$ & $\begin{array}{l}\text { Acordo Brasil - } \\
\text { Peru }\end{array}$ \\
\hline $\begin{array}{l}\text { Artigo VII } \\
\text { Reconhecimento } \\
\text { 1. Para efeito do } \\
\text { cumprimento, no } \\
\text { todo ou em parte, } \\
\text { de suas normas e } \\
\text { critérios para a } \\
\text { autorização, } \\
\text { licença ou } \\
\text { certificação de } \\
\text { prestadores de } \\
\text { serviços, e sujeito } \\
\text { às disposições do } \\
\text { parágrafo } 3 \text {, um } \\
\text { Membro poderá } \\
\text { reconhecer a } \\
\text { educação ou } \\
\text { experiência } \\
\text { adquirida, os } \\
\text { requisitos } \\
\text { cumpridos ou as } \\
\text { licenças ou } \\
\text { certificados } \\
\text { outorgados em } \\
\text { um determinado } \\
\text { país. Este } \\
\text { reconhecimento } \\
\text { poderá efetuar-se } \\
\text { mediante a } \\
\text { harmonização ou } \\
\text { de outro modo, } \\
\text { poderá basear-se } \\
\text { em acordo ou } \\
\text { convênio com o } \\
\text { país em questão } \\
\text { ou poderá ser } \\
\text { outorgado de } \\
\text { forma autônoma. } \\
2 . \text { Todo Membro } \\
\text { que seja parte em }\end{array}$ & $\begin{array}{l}\text { Artigo XI } \\
\text { Reconhecimento } \\
\text { 1. Quando um Estado } \\
\text { Parte reconhecer, de } \\
\text { forma unilateral ou } \\
\text { através de um } \\
\text { acordo, a educação, a } \\
\text { experiência, as } \\
\text { licenças, as } \\
\text { matrículas ou os } \\
\text { certificados obtidos } \\
\text { no território de outro } \\
\text { Estado Parte ou de } \\
\text { qualquer país que } \\
\text { não integre o } \\
\text { MERCOSUL: } \\
\text { a) nada do disposto } \\
\text { no presente Protocolo } \\
\text { será interpretado no } \\
\text { sentido de exigir a } \\
\text { esse Estado Parte que } \\
\text { reconheça a } \\
\text { educaçâ, a } \\
\text { experiência, as } \\
\text { licenças, as } \\
\text { matrículas ou os } \\
\text { certificados obtidos } \\
\text { no território de outro } \\
\text { Estado Parte; e } \\
\text { b) o Estado Parte } \\
\text { concederá a qualquer } \\
\text { outro Estado Parte } \\
\text { oportunidade } \\
\text { adequada para (i) } \\
\text { demonstrar que a } \\
\text { educação, a } \\
\text { experiência, as } \\
\text { licenças, as } \\
\text { matrículas e os } \\
\text { certificados obtidos }\end{array}$ & $\begin{array}{l}\text { Artigo VIII. } \\
\text { Reconhecimento } \\
\text { 1. Quando uma Parte } \\
\text { Signatária reconhecer, de } \\
\text { forma autônoma ou por } \\
\text { meio de um acordo, a } \\
\text { educação ou a } \\
\text { experiência adquirida, o } \\
\text { cumprimento dos } \\
\text { requisitos, as licenças ou } \\
\text { certificados outorgados } \\
\text { no território de outra } \\
\text { Parte Signatária ou de } \\
\text { qualquer país que não } \\
\text { seja Parte Signatária: } \\
\text { a) nada do disposto no } \\
\text { presente Protocolo será } \\
\text { interpretado no sentido de } \\
\text { exigir que essa Parte } \\
\text { Signatária conceda } \\
\text { reconhecimento à } \\
\text { educação ou experiência } \\
\text { adquirida, ao } \\
\text { cumprimento dos } \\
\text { requisitos, às licenças ou } \\
\text { aos certificados } \\
\text { outorgados no território } \\
\text { de outra Parte Signatária; } \\
\text { e } \\
\text { b) a Parte Signatária } \\
\text { concederá a qualquer } \\
\text { outra Parte Signatária } \\
\text { oportunidade adequada } \\
\text { para: } \\
\text { i) demonstrar que a } \\
\text { educação, a experiência, } \\
\text { as licenças e os } \\
\text { certificados outorgados } \\
\text { em seu território também } \\
\text { devam ser reconhecidos; }\end{array}$ & $\begin{array}{l}\text { Artigo 3.8: } \\
\text { Reconhecimento } \\
\text { 1. Para efeitos do } \\
\text { cumprimento, no } \\
\text { todo ou em parte, } \\
\text { de suas normas ou } \\
\text { critérios para } \\
\text { autorização, } \\
\text { licenciamento ou } \\
\text { certificação dos } \\
\text { prestadores de } \\
\text { serviços, e sujeito } \\
\text { às disposições do } \\
\text { parágrafo } 4, \text { uma } \\
\text { Parte poderá } \\
\text { reconhecer a } \\
\text { educação ou } \\
\text { experiência } \\
\text { adquiridas, os } \\
\text { requisitos } \\
\text { cumpridos, ou as } \\
\text { licenças ou } \\
\text { certificados } \\
\text { outorgados em um } \\
\text { país não Parte. Tal } \\
\text { reconhecimento, } \\
\text { que poderá se } \\
\text { efetuar mediante a } \\
\text { harmonização ou } \\
\text { de outro modo, } \\
\text { poderá se basear } \\
\text { em um acordo ou } \\
\text { convênio com o } \\
\text { país em questão ou } \\
\text { poderá ser } \\
\text { outorgado de } \\
\text { forma autônoma. } \\
2 . \text { Caso uma Parte } \\
\text { reconheça, } \\
\text { autonomamente ou }\end{array}$ \\
\hline
\end{tabular}




\begin{tabular}{|c|c|c|c|}
\hline \multicolumn{4}{|c|}{ Dispositivo de Regulamentação Doméstica nos Acordos do Brasil } \\
\hline GATS* & $\begin{array}{l}\text { Protocolo de } \\
\text { Montevidéu }\end{array}$ & $\begin{array}{l}\text { Acordo Mercosul - } \\
\text { Chile (ACE - 35) }\end{array}$ & $\begin{array}{l}\text { Acordo Brasil - } \\
\text { Peru }\end{array}$ \\
\hline $\begin{array}{l}\text { um acordo ou } \\
\text { convênio do tipo } \\
\text { a que se refere o } \\
\text { parágrafo 1, atual } \\
\text { ou futuro, } \\
\text { concederá } \\
\text { oportunidades } \\
\text { adequadas aos } \\
\text { demais Membros } \\
\text { interessados para } \\
\text { que negociem sua } \\
\text { adesão a tal } \\
\text { acordo ou } \\
\text { convênio ou para } \\
\text { que se negociem } \\
\text { com aqueles } \\
\text { outros } \\
\text { comparáveis. } \\
\text { Quando um } \\
\text { Membro outorgar } \\
\text { o reconhecimento } \\
\text { de forma } \\
\text { autônoma, } \\
\text { concederá aos } \\
\text { demais Membros } \\
\text { oportunidade } \\
\text { adequada para } \\
\text { que demonstrem } \\
\text { que a educação, a } \\
\text { experiência, as } \\
\text { licenças ou os } \\
\text { certificados } \\
\text { obtidos em seu } \\
\text { território devem } \\
\text { ser objeto de } \\
\text { reconhecimento. } \\
\text { 3. Nenhum } \\
\text { Membro } \\
\text { outorgará o } \\
\text { reconhecimento } \\
\text { de maneira que } \\
\text { constitua um } \\
\text { meio de } \\
\text { discriminação } \\
\text { entre países na } \\
\text { aplicação de suas } \\
\text { normas e critérios }\end{array}$ & $\begin{array}{l}\text { em seu território } \\
\text { também devam ser } \\
\text { reconhecidos; ou, (ii) } \\
\text { que possa celebrar } \\
\text { um acordo ou } \\
\text { convênio de efeito } \\
\text { equivalente. } \\
\text { 2. Cada Estado parte } \\
\text { se compromete a } \\
\text { alentar às entidades } \\
\text { competentes em seus } \\
\text { respectivos } \\
\text { territórios, entre } \\
\text { outras, às de natureza } \\
\text { governamental, assim } \\
\text { como associações e } \\
\text { colégios } \\
\text { profissionais, em } \\
\text { cooperação com } \\
\text { entidades } \\
\text { competentes dos } \\
\text { outros Estados } \\
\text { Partes, a desenvolver } \\
\text { normas e critérios } \\
\text { mutuamente } \\
\text { aceitáveis para o } \\
\text { exercício das } \\
\text { atividades e } \\
\text { profissões pertinentes } \\
\text { na esfera dos } \\
\text { serviços, através do } \\
\text { outorgamento de } \\
\text { licenças, matrículas e } \\
\text { certificados aos } \\
\text { prestadores de } \\
\text { serviços e a propor } \\
\text { recomendações ao } \\
\text { Grupo Mercado } \\
\text { Comum sobre } \\
\text { reconhecimento } \\
\text { mútuo. } \\
\text { 3. As normas e os } \\
\text { critérios referidos no } \\
\text { parágrafo } 2 \text { poderão } \\
\text { ser desenvolvidos, } \\
\text { entre outros, com } \\
\text { base nos seguintes }\end{array}$ & $\begin{array}{l}\text { ou, } \\
\text { ii) que possa celebrar } \\
\text { acordo ou convênio de } \\
\text { efeito equivalente. } \\
\text { 2. Na medida de suas } \\
\text { faculdades, cada Parte } \\
\text { Signatária estimulará as } \\
\text { autoridades competentes } \\
\text { em seus respectivos } \\
\text { territórios a desenvolver } \\
\text { normas e critérios } \\
\text { comuns que facilitem o } \\
\text { exercício das atividades } \\
\text { profissionais em matéria } \\
\text { de serviços. Quando se } \\
\text { alcançar acordo entre as } \\
\text { Partes Contratantes, as } \\
\text { recomendações } \\
\text { decorrentes serão } \\
\text { apresentadas à Comissão } \\
\text { Administradora do ACE } \\
\text { 35. } \\
\text { 3. As Partes Contratantes } \\
\text { comprometem-se a } \\
\text { realizar seus melhores } \\
\text { esforços para buscar o } \\
\text { aprofundamento das } \\
\text { matérias estabelecidas no } \\
\text { presente Artigo e se } \\
\text { reunirão com tal objetivo } \\
\text { um ano após a entrada em } \\
\text { vigor do presente } \\
\text { Protocolo. } \\
\text { 4. Nenhuma Parte } \\
\text { Signatária outorgará o } \\
\text { reconhecimento de modo } \\
\text { que constitua um meio de } \\
\text { discriminação entre as } \\
\text { Partes Signatárias na } \\
\text { aplicação de suas normas } \\
\text { ou critérios para a } \\
\text { autorização ou a } \\
\text { certificação dos } \\
\text { prestadores de serviços } \\
\text { ou a concessão de } \\
\text { licenças aos mesmos, ou }\end{array}$ & $\begin{array}{l}\text { por meio de um } \\
\text { acordo ou } \\
\text { convênio, a } \\
\text { educação ou } \\
\text { experiência } \\
\text { adquiridas, os } \\
\text { requisitos } \\
\text { cumpridos ou as } \\
\text { licenças ou } \\
\text { certificações } \\
\text { outorgadas no } \\
\text { território de um } \\
\text { país não Parte, } \\
\text { nada no Artigo } 3.3 \\
\text { (Tratamento de } \\
\text { NMF) será } \\
\text { interpretado no } \\
\text { sentido de exigir } \\
\text { que a Parte } \\
\text { outorgue tal } \\
\text { reconhecimento à } \\
\text { educação ou } \\
\text { experiência } \\
\text { adquiridas, os } \\
\text { requisitos } \\
\text { cumpridos ou as } \\
\text { licenças ou } \\
\text { certificados } \\
\text { outorgados no } \\
\text { território da outra } \\
\text { Parte. } \\
\text { 3. Uma Parte que } \\
\text { seja parte em um } \\
\text { acordo ou } \\
\text { convênio do tipo a } \\
\text { que se refere o } \\
\text { parágrafo 1, } \\
\text { existente ou futuro, } \\
\text { concederá } \\
\text { oportunidades } \\
\text { adequadas à outra } \\
\text { Parte, caso a outra } \\
\text { Parte estiver } \\
\text { interessada, para } \\
\text { que negocie sua } \\
\text { adesão a tal acordo } \\
\text { ou convênio ou }\end{array}$ \\
\hline
\end{tabular}




\begin{tabular}{|c|c|c|c|}
\hline \multicolumn{4}{|c|}{ Dispositivo de Regulamentação Doméstica nos Acordos do Brasil } \\
\hline GATS* & $\begin{array}{l}\text { Protocolo de } \\
\text { Montevidéu }\end{array}$ & \begin{tabular}{|l|} 
Acordo Mercosul - \\
Chile (ACE - 35) \\
\end{tabular} & $\begin{array}{l}\text { Acordo Brasil - } \\
\text { Peru }\end{array}$ \\
\hline $\begin{array}{l}\text { para a } \\
\text { autorização, } \\
\text { certificação ou } \\
\text { concessão de } \\
\text { licenças aos } \\
\text { provedores de } \\
\text { serviços, ou uma } \\
\text { restrição } \\
\text { encoberta ao } \\
\text { comércio de } \\
\text { serviços. } \\
\text { 4. Cada Membro: } \\
\text { a) em um prazo } \\
\text { de } 12 \text { meses a } \\
\text { partir da data em } \\
\text { que o Acordo } \\
\text { Constitutivo da } \\
\text { OMC tenha } \\
\text { efeito para si, } \\
\text { informará o } \\
\text { Conselho para o } \\
\text { Comércio de } \\
\text { Serviços das } \\
\text { medidas que } \\
\text { tenha em vigor } \\
\text { em matéria de } \\
\text { reconhecimento e } \\
\text { indicará se tais } \\
\text { medidas se } \\
\text { baseiam em } \\
\text { acordos ou } \\
\text { convênios do tipo } \\
\text { a que se refere o } \\
\text { parágrafo } 1 . \\
\text { b) informará } \\
\text { prontamente o } \\
\text { Conselho para o } \\
\text { Comércio de } \\
\text { Serviços tão } \\
\text { antecipadamente } \\
\text { quanto possível } \\
\text { do início de } \\
\text { negociações } \\
\text { sobre um acordo } \\
\text { ou convênio a } \\
\text { que se refere o } \\
\text { parágrafo 1. }\end{array}$ & $\begin{array}{l}\text { elementos: educação, } \\
\text { exames, experiência, } \\
\text { conduta e ética, } \\
\text { desenvolvimento } \\
\text { profissional e } \\
\text { renovação da } \\
\text { certificação, âmbito } \\
\text { de ação, } \\
\text { conhecimento local, } \\
\text { proteção ao } \\
\text { consumidor e } \\
\text { requisitos de } \\
\text { nacionalidade, } \\
\text { residência ou } \\
\text { domicílio. } \\
\text { 4. Uma vez recebida } \\
\text { a recomendação } \\
\text { referida no parágrafo } \\
\text { 2, o Grupo Mercado } \\
\text { Comum a examinará } \\
\text { dentro de um prazo } \\
\text { razoável para } \\
\text { determinar a sua } \\
\text { consistência com este } \\
\text { Protocolo. Baseando- } \\
\text { se neste exame, cada } \\
\text { Estado Parte se } \\
\text { compromete a } \\
\text { encarregar a suas } \\
\text { respectivas } \\
\text { autoridades } \\
\text { competentes, quando } \\
\text { assim for necessário, } \\
\text { a implementação do } \\
\text { decidido pelas } \\
\text { instâncias } \\
\text { competentes do } \\
\text { MERCOSUL, dentro } \\
\text { de um período } \\
\text { mutuamente } \\
\text { acordado. } \\
\text { 5. O Grupo Mercado } \\
\text { Comum examinará } \\
\text { periodicamente e, no } \\
\text { mínimo uma vez a } \\
\text { cada três anos, a }\end{array}$ & $\begin{array}{l}\text { uma restrição encoberta } \\
\text { ao comércio de serviços. }\end{array}$ & $\begin{array}{l}\text { para que negocie } \\
\text { com ela outro } \\
\text { acordo ou } \\
\text { convênio em } \\
\text { termos } \\
\text { comparáveis. Caso } \\
\text { uma Parte } \\
\text { outorgue o } \\
\text { reconhecimento } \\
\text { autonomamente, } \\
\text { concederá à outra } \\
\text { Parte } \\
\text { oportunidades } \\
\text { adequadas para que } \\
\text { demonstre que a } \\
\text { educação, a } \\
\text { experiência, as } \\
\text { licenças ou } \\
\text { certificações } \\
\text { obtidas ou os } \\
\text { requisitos } \\
\text { cumpridos no } \\
\text { território dessa } \\
\text { outra Parte devem } \\
\text { ser objeto de } \\
\text { reconhecimento. } \\
\text { 4. Nenhuma Parte } \\
\text { outorgará o } \\
\text { reconhecimento de } \\
\text { maneira que } \\
\text { constitua um meio } \\
\text { de discriminação } \\
\text { entre países na } \\
\text { aplicação de suas } \\
\text { normas ou critérios } \\
\text { para a autorização } \\
\text { ou certificação dos } \\
\text { prestadores de } \\
\text { serviços ou a } \\
\text { concessão de } \\
\text { licenças aos } \\
\text { mesmos, ou uma } \\
\text { restrição encoberta } \\
\text { ao comércio de } \\
\text { serviços. }\end{array}$ \\
\hline
\end{tabular}




\begin{tabular}{|c|c|c|c|}
\hline \multicolumn{4}{|c|}{ Dispositivo de Regulamentação Doméstica nos Acordos do Brasil } \\
\hline GATS* & $\begin{array}{l}\text { Protocolo de } \\
\text { Montevidéu } \\
\end{array}$ & $\begin{array}{l}\text { Acordo Mercosul - } \\
\text { Chile (ACE - 35) }\end{array}$ & $\begin{array}{l}\text { Acordo Brasil - } \\
\text { Peru }\end{array}$ \\
\hline $\begin{array}{l}\text { c) informará } \\
\text { prontamente o } \\
\text { Conselho para o } \\
\text { Comércio de } \\
\text { Serviços quando } \\
\text { adotar novas } \\
\text { medidas em } \\
\text { matéria de } \\
\text { reconhecimento } \\
\text { ou modificar } \\
\text { sensivelmente as } \\
\text { existentes e } \\
\text { indicará se as } \\
\text { medidas se } \\
\text { baseiam em um } \\
\text { acordo a que se } \\
\text { refere o parágrafo } \\
\text { 1. } \\
5 . \text { Sempre que for } \\
\text { apropriado, o } \\
\text { reconhecimento } \\
\text { deveria ser } \\
\text { baseado em } \\
\text { critérios } \\
\text { acordados } \\
\text { multilateralmente } \\
\text {. Nos casos em } \\
\text { que for } \\
\text { apropriado, os } \\
\text { Membros } \\
\text { trabalharão em } \\
\text { colaboração com } \\
\text { organizações } \\
\text { intergovernament } \\
\text { ais e não } \\
\text { governamentais } \\
\text { competentes com } \\
\text { vistas ao } \\
\text { estabelecimento e } \\
\text { adoção de } \\
\text { normas e critérios } \\
\text { internacionais } \\
\text { comuns em } \\
\text { matéria de } \\
\text { reconhecimento e } \\
\text { de normas } \\
\text { internacionais }\end{array}$ & $\begin{array}{l}\text { implementação deste } \\
\text { Artigo. }\end{array}$ & & \\
\hline
\end{tabular}




\begin{tabular}{|l|l|l|l|}
\hline \multicolumn{4}{|c|}{ Dispositivo de Regulamentação Doméstica nos Acordos do Brasil } \\
\hline GATS* & $\begin{array}{l}\text { Protocolo de } \\
\text { Montevidéu }\end{array}$ & $\begin{array}{l}\text { Acordo Mercosul - } \\
\text { Chile (ACE - 35) }\end{array}$ & $\begin{array}{l}\text { Acordo Brasil - } \\
\text { Peru }\end{array}$ \\
\hline $\begin{array}{l}\text { comuns para o } \\
\text { exercício das } \\
\text { atividades e } \\
\text { profissões } \\
\text { pertinentes em } \\
\text { matéria de } \\
\text { serviços. }\end{array}$ & & & \\
\hline
\end{tabular}

Fonte: MDIC, ALADI e Planalto.

GATS: <http://www.mdic.gov.br/arquivos/dwnl_1244492330.pdf>.

Acordo Mercosul-Chile:

$<$ http://www.aladi.org/nsfaladi/textacdos.nsf/f7a2d493807d9e8c032574e100640526/6ba70 a0157ba3e3e03257f79005ea54e?OpenDocument $>$.

Protocolo de Montevidéu: <http://www.planalto.gov.br/ccivil_03/_ato2007-

2010/2008/decreto/d6480.htm>.

Acordo Brasil-Peru: <http://www.mdic.gov.br/index.php/comércio-exterior/negociacoesinternacionais/9-assuntos/categ-comércio-exterior/1508-acordo-de-ampliacao-economicocomercial-brasil-peru-ainda-sem-vigencia $>$.

* Conforme Projeto Releitura: Artigo VII.2 A expressão “para que se negociem com aqueles outros comparáveis", na terceira linha, não representa uma tradução adequada das versões oficiais desse Artigo. Na língua portuguesa, poderia ser substituída pela expressão “(...) concederá oportunidades adequadas aos demais Membros interessados para que negociem a sua adesão a tal acordo ou convênio ou para que sejam negociados acordos comparáveis". Na última linha do parágrafo 2 , houve a supressão do termo "requirements met" da versão inglesa. Dessa forma, com as propostas, o texto do Artigo VII.2 ficaria dessa forma: “(...) as licenças, ou certificados obtidos ou os requisitos cumpridos”. Artigo VII.4 Uma parte importante do item (b) não consta na versão em português, a saber: a expressão: "in order to provide adequate opportunity to any other Member to indicate their interest in participating in the negotiations before they enter a substantive phase". Tal trecho poderia ter sido traduzido como "com o intuito de se prover adequadas oportunidades para que qualquer Membro indique seu interesse em participar das negociações antes que estas deem início a suas fases substanciais". No item (c) desse mesmo Artigo, foi suprimido o termo "arrangement", presente nas versões oficiais. Ressalte-se que, nos itens VII.4 (a) e (b), a mesma expressão incluía a palavra "convênio". Sendo assim, deve-se incluir o termo "convênio" na última linha do subitem (c). Artigo VII.5 Na versão portuguesa, o verbo "deveria" corresponderia melhor às versões oficiais do texto legal se tivesse sido traduzido como "deverá". Na versão espanhola, esse é o verbo utilizado. $\mathrm{O}$ uso do modo indicativo enfatiza o caráter normativo. Por fim, o adjetivo "competentes", na versão em português (terceira linha), não encontra correspondência exata na versão inglesa. Contudo, a versão em francês assemelha-se à versão em português, trazendo o adjetivo "compétentes" para qualificar organizações intergovernamentais e não governamentais. Da mesma forma, o adjetivo "competentes" é utilizado na versão em espanhol. Por essa razão, não haveria necessidade de alteração da expressão utilizada no Decreto $n^{0} 1.355 / 94$. No entanto, uma possível sugestão de tradução seria usar os adjetivos "relevantes", ou "atuantes" para qualificar as organizações em questão. Disponível em: $<$ http://ccgi.fgv.br/sites/ccgi.fgv.br/files/file/Publicacoes/14\%20Acordo\%20Geral\%20sobr 
e\%20o\%20Com\%C3\%A9rcio\%20de\%20Servi\%C3\%A7os\%20\%28GATS\%29.pdf $>$. Acesso em: 21 out. 2017. 


\section{ANEXO IV}

MAPEAMENTO DE DISPOSITIVOS DOS CAPÍTULOS DE SERVIÇOS DO TPP DE COERÊNCIA REGULATÓRIA

\begin{tabular}{|c|c|}
\hline Capítulo & Texto \\
\hline \multirow{3}{*}{$\begin{array}{c}\text { Chapter } 10 \text { - Cross Border } \\
\text { Trade in Service }\end{array}$} & $\begin{array}{l}\text { Article 10.3: National Treatment } 2 \\
\text { 1. Each Party shall accord to services and service } \\
\text { suppliers of another Party treatment no less favourable } \\
\text { than that it accords, in like circumstances, to its own } \\
\text { services and service suppliers. } \\
\text { 2. For greater certainty, the treatment to be accorded } \\
\text { by a Party under paragraph } 1 \text { means, with respect to a } \\
\text { regional level of government, treatment no less } \\
\text { favourable than the most favourable treatment } \\
\text { accorded, in like circumstances, by that regional level } \\
\text { of government to service suppliers of the Party of } \\
\text { which it forms a part. } \\
2 \text { For greater certainty, whether treatment is accorded } \\
\text { in "like circumstances" under Article } 10.3 \text { (National } \\
\text { Treatment) or Article } 10.4 \text { (Most-Favoured-Nation } \\
\text { Treatment) depends on the totality of the } \\
\text { circumstances, including whether the relevant } \\
\text { treatment distinguishes between services or service } \\
\text { suppliers on the basis of legitimate public welfare } \\
\text { objectives. }\end{array}$ \\
\hline & $\begin{array}{l}\text { Article 10.4: Most-Favoured-Nation Treatment } \\
\text { Each Party shall accord to services and service } \\
\text { suppliers of another Party treatment no less favourable } \\
\text { than that it accords, in like circumstances, to services } \\
\text { and service suppliers of any other Party or a non- } \\
\text { Party. }\end{array}$ \\
\hline & $\begin{array}{l}\text { Article 10.5: Market Access } \\
\text { No Party shall adopt or maintain, either on the basis of } \\
\text { a regional subdivision or on the basis of its entire } \\
\text { territory, measures that: } \\
\text { (a) impose limitations on: } \\
\text { (i) the number of service suppliers, whether in the } \\
\text { form of numerical quotas, monopolies, exclusive } \\
\text { service suppliers or the requirement of an economic } \\
\text { needs test; } \\
\text { (ii) the total value of service transactions or assets in } \\
\text { the form of numerical quotas or the requirement of an } \\
\text { economic needs test; } \\
\text { (iii) the total number of service operations or the total } \\
\text { quantity of service output expressed in terms of } \\
\text { designated numerical units in the form of quotas or } \\
\text { the requirement of an economic needs test; } 3 \text { or } \\
\text { (iv) the total number of natural persons that may be } \\
\text { employed in a particular service sector or that a }\end{array}$ \\
\hline
\end{tabular}




\begin{tabular}{|c|c|}
\hline Capítulo & Texto \\
\hline & $\begin{array}{l}\text { service supplier may employ and who are necessary } \\
\text { for, and directly related to, the supply of a specific } \\
\text { service in the form of numerical quotas or the } \\
\text { requirement of an economic needs test; or } \\
\text { (b) restrict or require specific types of legal entity or } \\
\text { joint venture through which a service supplier may } \\
\text { supply a service. } \\
3 \text { Subparagraph (a)(iii) does not cover measures of a } \\
\text { Party which limit inputs for the supply of services. }\end{array}$ \\
\hline & $\begin{array}{l}\text { Article 10.8: Domestic Regulation } \\
\text { 1. Each Party shall ensure that all measures of general } \\
\text { application affecting trade in services are administered } \\
\text { in a reasonable, objective and impartial manner. } \\
\text { 2. With a view to ensuring that measures relating to } \\
\text { qualification requirement s and } \\
\text { procedures, technical standards and licensing } \\
\text { requirements do not constitute unnecessary barriers to } \\
\text { trade in services, while recognising the right to } \\
\text { regulate and to introduce new regulations on the } \\
\text { supply of services in order to meet its policy } \\
\text { objectives, each Party shall endeavour to ensure that } \\
\text { any such measures that it adopts or maintains are: (a) } \\
\text { based on objective and transparent criteria, such as } \\
\text { competence and the ability to supply the service; and } \\
\text { (b) in the case of licensing procedures, not in } \\
\text { themselves a restriction on the supply of the service. } \\
\text { 3. In determining whether a Party is in conformity } \\
\text { with its obligations under paragraph } 2 \text {, account shall } \\
\text { be taken of international standards of relevant } \\
\text { international organisations applied by that Party. } \\
\text { 4. If a Party requires authorisation for the supply of a } \\
\text { service, it shall ensure that its competent authorities: } \\
\text { (a) within a reasonable period of time after the } \\
\text { submission of an application considered complete } \\
\text { under its laws and regulations, inform the applicant of } \\
\text { the decision concerning the application; } \\
\text { (b) to the extent practicable, establish an indicative } \\
\text { timeframe for the processing of an application; } \\
\text { (c) if an application is rejected, to the extent } \\
\text { practicable, inform the applicant of the reasons for the } \\
\text { rejection, either directly or on request, as appropriate; } \\
\text { (d) on request of the applicant, provide, without undue } \\
\text { delay, information concerning the status of the } \\
\text { application; } \\
\text { (e) to the extent practicable, provide the applicant } \\
\text { with the opportunity to correct minor errors and } \\
\text { omissions in the application and endeavour to provide } \\
\text { guidance on the additional information required; and }\end{array}$ \\
\hline
\end{tabular}




\begin{tabular}{|c|c|}
\hline Capítulo & Texto \\
\hline & $\begin{array}{l}\text { (f) if they deem appropriate, accept copies of } \\
\text { documents that are authenticated in accordance with } \\
\text { the Party's laws in place of original documents. } \\
\text { 5. Each Party shall ensure that any authorisation fee } \\
\text { charged by any of its competent authorities is } \\
\text { reasonable, transparent and does not, in itself, restrict } \\
\text { the supply of the relevant service.7 } \\
\text { 6. If licensing or qualification requirements include } \\
\text { the completion of an examination, each Party shall } \\
\text { ensure that: } \\
\text { (a) the examination is scheduled at reasonable } \\
\text { intervals; and } \\
\text { (b) a reasonable period of time is provided to enable } \\
\text { interested persons to submit an application. } \\
\text { 7. Each Party shall ensure that there are procedures in } \\
\text { place domestically to assess the competency of } \\
\text { professionals of another Party. } \\
8 \text {. Paragraphs } 1 \text { through } 7 \text { shall not apply to the non- } \\
\text { conforming aspects of measures that are not subject to } \\
\text { the obligations under Article } 10.3 \text { (National } \\
\text { Treatment) or Article } 10.5 \text { (Market Access) by reason } \\
\text { of an entry in a Party's Schedule to Annex I, or to } \\
\text { measures that are not subject to the obligations under } \\
\text { Article } 10.3 \text { (National Treatment) or Article } 10.5 \\
\text { (Market Access) by reason of an entry in a Party's } \\
\text { Schedule to Annex II. } \\
\text { 9. If the results of the negotiations related to } \\
\text { paragraph } 4 \text { of Article VI of GATS, or the results of } \\
\text { any similar negotiations undertaken in other } \\
\text { multilateral fora in which the Parties participate, enter } \\
\text { into effect, the Parties shall jointly review these } \\
\text { results with a view to bringing them into effect, as } \\
\text { appropriate, under this Agreement. } \\
6 \text { "Relevant international organisations" refers to } \\
\text { international bodies whose membership is open to the } \\
\text { relevant bodies of at least all Parties to the } \\
\text { Agreement. } \\
7 \text { For the purposes of this paragraph, authorisation } \\
\text { fees do not include fees for the use of natural } \\
\text { resources, payments for auction, tendering or other } \\
\text { non-discriminatory means of awarding concessions, } \\
\text { or mandated contributions to universal service } \\
\text { provision. }\end{array}$ \\
\hline
\end{tabular}




\begin{tabular}{|c|c|}
\hline Capítulo & Texto \\
\hline & $\begin{array}{l}\text { Article 10.9: Recognition } \\
\text { 1. For the purposes of the fulfilment, in whole or in } \\
\text { part, of a Party's standards or criteria for the } \\
\text { authorisation, licensing or certification of service } \\
\text { suppliers, and subject to the requirements of } \\
\text { paragraph 4, it may recognise the education or } \\
\text { experience obtained, requirements met, or licences or } \\
\text { certifications granted, in the territory of another Party } \\
\text { or a non-Party. That recognition, which may be } \\
\text { achieved through harmonisation or otherwise, } \\
\text { may be based on an agreement or arrangement } \\
\text { with the Party or non-Party concerned, or may be } \\
\text { accorded autonomously. } \\
\text { 2. If a Party recognises, autonomously or by } \\
\text { agreement or arrangement, the education or } \\
\text { experience obtained, requirements met, or licenses or } \\
\text { certifications granted, in the territory of another Party } \\
\text { or a non-Party, nothing in Article } 10.4 \text { (Most- } \\
\text { Favoured-Nation Treatment) shall be construed to } \\
\text { require the Party to accord recognition to the } \\
\text { education or experience obtained, requirements met, } \\
\text { or licenses or certifications granted, in the territory of } \\
\text { any other Party. } \\
\text { 3. A Party that is a party to an agreement or } \\
\text { arrangement of the type referred to in paragraph } 1 \text {, } \\
\text { whether existing or future, shall afford adequate } \\
\text { opportunity to another Party, on request, to negotiate } \\
\text { its accession to that agreement or arrangement, or to } \\
\text { negotiate a comparable agreement or arrangement. If a } \\
\text { Party accords recognition autonomously, it shall } \\
\text { afford adequate opportunity to another Party to } \\
\text { demonstrate that education, experience, licences or } \\
\text { certifications obtained or requirements met in that } \\
\text { other Party's territory should be recognised. } \\
4 . \text { A Party shall not accord recognition in a manner } \\
\text { that would constitute a means of discrimination } \\
\text { between Parties or between Parties and non-Parties in } \\
\text { the application of its standards or criteria for the } \\
\text { authorisation, licensing or certification of service } \\
\text { suppliers, or a disguised restriction on trade in } \\
\text { services. } \\
\text { 5. As set out in Annex 10-A (Professional Services), } \\
\text { the Parties shall endeavour to facilitate trade in } \\
\text { professional services, including through the } \\
\text { establishment of a Professional Services Working } \\
\text { Group. }\end{array}$ \\
\hline
\end{tabular}




\begin{tabular}{|c|c|}
\hline Capítulo & \begin{tabular}{|l} 
Texto \\
\end{tabular} \\
\hline & $\begin{array}{l}\text { Article 10.11: Transparency } \\
\text { 1. Each Party shall maintain or establish appropriate } \\
\text { mechanisms for responding to inquiries from } \\
\text { interested persons regarding its regulations that relate } \\
\text { to the subject matter of this Chapter. } 8 \\
\text { 2. If a Party does not provide advance notice and } \\
\text { opportunity for comment pursuant to Article } 26.2 .2 \\
\text { (Publication) with respect to regulations that relate to } \\
\text { the subject matter in this Chapter, it shall, to the } \\
\text { extent practicable, provide in writing or otherwise } \\
\text { notify interested persons of the reasons for not doing } \\
\text { so. } \\
\text { 3. To the extent possible, each Party shall allow } \\
\text { reasonable time between publication of final } \\
\text { regulations and the date when they enter into effect. }\end{array}$ \\
\hline & $\begin{array}{l}\text { Annex 10-A - Professional Services } \\
\text { General Provisions } \\
\text { 1. Each Party shall consult with relevant bodies in its } \\
\text { territory to seek to identify professional services when } \\
\text { two or more Parties are mutually interested in } \\
\text { establishing dialogue on issues that relate to the } \\
\text { recognition of professional qualifications, licensing or } \\
\text { registration. } \\
\text { 2. Each Party shall encourage its relevant bodies to } \\
\text { establish dialogues with the relevant bodies of other } \\
\text { Parties, with a view to recognising professional } \\
\text { qualifications, and facilitating licensing or registration } \\
\text { procedures. } \\
\text { 3. Each Party shall encourage its relevant bodies to } \\
\text { take into account agreements that relate to } \\
\text { professional services in the development of } \\
\text { agreements on the recognition of professional } \\
\text { qualifications, licensing and registration. } \\
\text { (...) } \\
\text { Engineering and Architectural Services } \\
\text { 5. Further to paragraph } 3 \text {, the Parties recognise the } \\
\text { work in APEC to promote the mutual recognition of } \\
\text { professional competence in engineering and } \\
\text { architecture, and the professional mobility of these } \\
\text { professions, under the APEC Engineer and APEC } \\
\text { Architect frameworks. } \\
\text { 6. Each Party shall encourage its relevant bodies to } \\
\text { work towards becoming authorised to operate APEC } \\
\text { Engineer and APEC Architect Registers. } \\
\text { 7. A Party shall encourage its relevant bodies } \\
\text { operating APEC Engineer or APEC Architect } \\
\text { Registers to enter into mutual recognition } \\
\text { arrangements with the relevant bodies of other Parties } \\
\text { operating those registers. }\end{array}$ \\
\hline
\end{tabular}




\begin{tabular}{|c|c|}
\hline Capítulo & Texto \\
\hline & $\begin{array}{l}\text { Temporary Licensing or Registration of Engineers } \\
\text { 8. Further to paragraph 4, in taking steps to } \\
\text { implement a temporary or project-specific licensing or } \\
\text { registration regime for engineers, a Party shall consult } \\
\text { with its relevant professional bodies with respect to } \\
\text { any recommendations for: } \\
\text { (a) the development of procedures for the temporary } \\
\text { licensing or registration of engineers of another Party } \\
\text { to permit them to practise their engineering specialties } \\
\text { in its territory; } \\
\text { (b) the development of model procedures for } \\
\text { adoption by the competent authorities throughout its } \\
\text { territory to facilitate the temporary licensing or } \\
\text { registration of those engineers; } \\
\text { (c) the engineering specialties to which priority } \\
\text { should be given in developing temporary licensing or } \\
\text { registration procedures; and } \\
\text { (d) other matters relating to the temporary licensing } \\
\text { or registration of engineers identified in the } \\
\text { consultations. } \\
\text { Legal Services } \\
\text { 9. The Parties recognise that transnational legal } \\
\text { services that cover the laws of multiple jurisdictions } \\
\text { play an essential role in facilitating trade and } \\
\text { investment and in promoting economic growth and } \\
\text { business confidence. } \\
\text { 10. If a Party regulates or seeks to regulate foreign } \\
\text { lawyers and transnational legal practice, the Party } \\
\text { shall encourage its relevant bodies to consider, subject } \\
\text { to its laws and regulations, whether or in what } \\
\text { manner: } \\
\text { (a) foreign lawyers may practise foreign law on the } \\
\text { basis of their right to practise that law in their home } \\
\text { jurisdiction; } \\
\text { (b) foreign lawyers may prepare for and appear in } \\
\text { commercial arbitration, conciliation and mediation } \\
\text { proceedings; } \\
\text { (c) local ethical, conduct and disciplinary standards } \\
\text { are applied to foreign lawyers in a manner that is no } \\
\text { more burdensome for foreign lawyers than the } \\
\text { requirements imposed on domestic (host country) } \\
\text { lawyers; } \\
\text { (d) alternatives for minimum residency requirements } \\
\text { are provided for foreign lawyers, such as requirements } \\
\text { that foreign lawyers disclose to clients their status as a } \\
\text { foreign lawyer, or maintain professional indemnity } \\
\text { insurance or alternatively disclose to clients that they } \\
\text { (e) the following modes of providing transnational }\end{array}$ \\
\hline
\end{tabular}




\begin{tabular}{|c|c|}
\hline Capítulo & Texto \\
\hline & $\begin{array}{l}\text { legal services are accommodated: } \\
\text { (i) on a temporary fly-in, fly-out basis; } \\
\text { (ii) through the use of web-based or } \\
\text { telecommunications technology; } \\
\text { (iii) by establishing a commercial presence; and } \\
\text { (iv) through a combination of fly-in, fly-out and one } \\
\text { or both of the other modes listed in subparagraphs (ii) } \\
\text { and (iii); } \\
\text { (f) foreign lawyers and domestic (host country) } \\
\text { lawyers may work together in the delivery of fully } \\
\text { integrated transnational legal services; and } \\
\text { (g) a foreign law firm may use the firm name of its } \\
\text { choice. } \\
\text { Professional Services Working Group } \\
\text { 11. The Parties hereby establish a Professional } \\
\text { Services Working Group (Working Group), composed } \\
\text { of representatives of each Party, to facilitate the } \\
\text { activities listed in paragraphs } 1 \text { through } 4 \text {. } \\
\text { 12. The Working Group shall liaise, as appropriate, to } \\
\text { support the Parties' relevant professional and } \\
\text { regulatory bodies in pursuing the activities listed in } \\
\text { paragraphs } 1 \text { through } 4 \text {. This support may include } \\
\text { providing points of contact, facilitating meetings and } \\
\text { providing information regarding regulation of } \\
\text { professional services in the Parties' territories. } \\
\text { 13. The Working Group shall meet annually, or as } \\
\text { agreed by the Parties, to discuss progress towards the } \\
\text { objectives in paragraphs } 1 \text { through } 4 \text {. For a meeting } \\
\text { to be held, at least two Parties must participate. It is } \\
\text { not necessary for representatives of all Parties to } \\
\text { participate in order to hold a meeting of the Working } \\
\text { Group. } \\
\text { 14. The Working Group shall report to the } \\
\text { Commission on its progress and on the future } \\
\text { direction of its work, within two years of the date of } \\
\text { entry into force of this Agreement. } \\
\text { 15. Decisions of the Working Group shall have effect } \\
\text { only in relation to those Parties that participated in the } \\
\text { meeting at which the decision was taken, except if: } \\
\text { (a) otherwise agreed by all Parties; or } \\
\text { (b) a Party that did not participate in the meeting } \\
\text { requests to be covered by the decision and all Parties } \\
\text { originally covered by the decision agree. }\end{array}$ \\
\hline $\begin{array}{c}\text { CHAPTER } 12 \\
\text { TEMPORARY ENTRY FOR } \\
\text { BUSINESS PERSONS }\end{array}$ & $\begin{array}{l}\text { Article 12.5: Business Travel } \\
\text { The Parties affirm their commitments to each other in } \\
\text { the context of APEC to enhance the mobility of } \\
\text { business persons, including through exploration and } \\
\text { voluntary development of trusted traveller }\end{array}$ \\
\hline
\end{tabular}




\begin{tabular}{|c|c|}
\hline \multirow[t]{3}{*}{ Capítulo } & Texto \\
\hline & $\begin{array}{l}\text { programmes, and their support for efforts to enhance } \\
\text { the APEC Business Travel Card programme. }\end{array}$ \\
\hline & $\begin{array}{l}\text { Article 12.8: Cooperation } \\
\text { Recognising that the Parties can benefit from sharing } \\
\text { their diverse experience in developing and applying } \\
\text { procedures related to visa processing and border } \\
\text { security, the Parties shall consider undertaking } \\
\text { mutually agreed cooperation activities, subject to } \\
\text { available resources, including by: (a) providing advice } \\
\text { on the development and implementation of electronic } \\
\text { processing systems for visas; (b) sharing experiences } \\
\text { with regulations, and the implementation of } \\
\text { programmes and } \\
\text { technology related to: (i) border security, including } \\
\text { those related to the use of biometric technology, } \\
\text { advanced passenger information systems, frequent } \\
\text { passenger programmes } \\
\text { and security in travel documents; and (ii) the } \\
\text { expediting of certain categories of applicants in order } \\
\text { to reduce facility and workload constraints; and (c) } \\
\text { cooperating in multilateral fora to promote processing } \\
\text { enhancements, such as those listed in subparagraphs } \\
\text { (a) and (b). }\end{array}$ \\
\hline $\begin{array}{c}\text { CHAPTER } 13 \\
\text { TELECOMMUNICATIONS }\end{array}$ & $\begin{array}{l}\text { Article 13.3: Approaches to Regulation } \\
\text { 1.The Parties recognise the value of competitive } \\
\text { markets to deliver a wide choice in the supply of } \\
\text { telecommunications services and to enhance } \\
\text { consumer welfare, and that economic regulation may } \\
\text { not be needed if there is effective competition or if a } \\
\text { service is new to a market. } \\
\text { Accordingly, the Parties recognise that regulatory } \\
\text { needs and approaches differ market by market, and } \\
\text { that each Party may determine how to implement its } \\
\text { obligations } \\
\text { under this Chapter. } \\
\text { 2. In this respect, the Parties recognise that a Party } \\
\text { may: (a) engage in direct regulation either in } \\
\text { anticipation of an issue that the Party expects may } \\
\text { arise or to resolve an issue that has already arisen in } \\
\text { the market; (b) rely on the role of market forces, } \\
\text { particularly with respect to market segments that are, } \\
\text { or are likely to be, competitive or that have low } \\
\text { barriers to entry, such as } \\
\text { services provided by telecommunications suppliers } \\
\text { that do not own network facilities; } 2 \text { or (c) use any } \\
\text { other appropriate means that benefit the long-term } \\
\text { interest of end -users. } \\
\text { 3. When a Party engages in direct regulation, it may }\end{array}$ \\
\hline
\end{tabular}




\begin{tabular}{|c|c|}
\hline Capítulo & Texto \\
\hline & $\begin{array}{l}\text { nonetheless forbear, to the extent provided for in its } \\
\text { law, from applying that regulation to a service that the } \\
\text { Party classifies as a public telecommunications } \\
\text { service, if its telecommunications regulatory body or } \\
\text { other competent } \\
\text { body determines that: (a) enforcement of the } \\
\text { regulation is not necessary to prevent unreasonable or } \\
\text { discriminatory practices; (b) enforcement of the } \\
\text { regulation is not necessary for the protection of } \\
\text { consumers; and (c) forbearance is consistent with the } \\
\text { public interest, including promoting and } \\
\text { enhancing competition between suppliers of public } \\
\text { telecommunications services. } \\
2 \text { Consistent with paragraph 2(b), the United States, } \\
\text { based on its evaluation of the state of competition of } \\
\text { the U.S. commercial mobile market, has not applied } \\
\text { major supplier-related measures pursuant to Articles } \\
\text { 13.7 (Treatment by Major Suppliers of Public } \\
\text { Telecommunication Services), 13.9.2 (Resale), } 13.11 \\
\text { (Interconnection with Major Suppliers), 13.13 (Co- } \\
\text { Location by Major Suppliers), or } 13.14 \text { (Access to } \\
\text { Poles, Ducts,Conduits and Rights-of-Way Owned or } \\
\text { Controlled by Major Suppliers) to the commercial } \\
\text { mobile market. }\end{array}$ \\
\hline & $\begin{array}{l}\text { Article 13.25: Relation to International } \\
\text { Organisations } \\
\text { The Parties recognise the importance of international } \\
\text { standards for global compatibility and interoperability } \\
\text { of telecommunications networks and services and } \\
\text { undertake to promote those standards through the } \\
\text { work of relevant international organisations. }\end{array}$ \\
\hline & $\begin{array}{l}\text { Article 13.26: Committee on Telecommunications } \\
\text { 1. The Parties hereby establish a Committee on } \\
\text { Telecommunications (Committee) composed of } \\
\text { government representatives of each Party. } \\
\text { 2. The Committee shall: } \\
\text { (a) review and monitor the implementation and } \\
\text { operation of this Chapter, with a view to ensuring the } \\
\text { effective implementation of the Chapter by enabling } \\
\text { responsiveness to technological and regulatory } \\
\text { developments in telecommunications to ensure the } \\
\text { continuing relevance of this Chapter to Parties, } \\
\text { service suppliers and end users; } \\
\text { (b) discuss any issues related to this Chapter and any } \\
\text { other issues relevant to the telecommunications sector } \\
\text { as may be decided by the Parties; } \\
\text { (c) report to the Commission on the findings and the } \\
\text { outcomes of discussions of the Committee; and } \\
\text { (d) carry out other functions delegated to it by the }\end{array}$ \\
\hline
\end{tabular}




\begin{tabular}{|c|c|}
\hline Capítulo & Texto \\
\hline & $\begin{array}{l}\text { Commission. } \\
\text { 3. The Committee shall meet at such venues and times } \\
\text { as the Parties may decide. } \\
\text { 4. The Parties may decide to invite representatives of } \\
\text { relevant entities other than the Parties, including } \\
\text { representatives of private sector entities, having the } \\
\text { necessary expertise relevant to the issues to be } \\
\text { discussed, to attend meetings of the Committee. }\end{array}$ \\
\hline \multirow{3}{*}{$\begin{array}{c}\text { CHAPTER } 14 \\
\text { ELECTRONIC COMMERCE }\end{array}$} & $\begin{array}{l}\text { Article 14.5: Domestic Electronic Transactions } \\
\text { Framework } \\
\text { 1. Each Party shall maintain a legal framework } \\
\text { governing electronic transactions consistent with the } \\
\text { principles of the UNCITRAL Model Law on } \\
\text { Electronic Commerce } 1996 \text { or the United Nations } \\
\text { Convention on the Use of Electronic Communications } \\
\text { in International Contracts, done at New York } \\
\text { November 23, 2005. } \\
\text { 2. Each Party shall endeavour to: } \\
\text { (a) avoid any unnecessary regulatory burden on } \\
\text { electronic transactions; and } \\
\text { (b) facilitate input by interested persons in the } \\
\text { development of its legal framework for electronic } \\
\text { transactions. }\end{array}$ \\
\hline & $\begin{array}{l}\text { Article 14.7: Online Consumer Protection } \\
\text { 1. The Parties recognise the importance of adopting } \\
\text { and maintaining transparent and effective measures to } \\
\text { protect consumers from fraudulent and deceptive } \\
\text { commercial activities as referred to in Article } 16.7 .2 \\
\text { (Consumer Protection) when they engage in electronic } \\
\text { commerce. } \\
\text { 2. Each Party shall adopt or maintain consumer } \\
\text { protection laws to proscribe fraudulent and deceptive } \\
\text { commercial activities that cause harm or potential } \\
\text { harm to consumers engaged in online commercial } \\
\text { activities. } \\
3 \text {. The Parties recognise the importance of } \\
\text { cooperation between their respective national } \\
\text { consumer protection agencies or other relevant bodies } \\
\text { on activities related to cross-border electronic } \\
\text { commerce in order to enhance consumer welfare. To } \\
\text { this end, the Parties affirm that the cooperation sought } \\
\text { under Article } 16.7 .5 \text { and Article } 16.7 .6 \text { (Consumer } \\
\text { Protection) includes cooperation with respect to } \\
\text { online commercial activities. }\end{array}$ \\
\hline & $\begin{array}{l}\text { Article 14.8: Personal Information Protection5 } \\
\text { 1. The Parties recognise the economic and social } \\
\text { benefits of protecting the personal information of } \\
\text { users of electronic commerce and the contribution that } \\
\text { this makes to enhancing consumer confidence in }\end{array}$ \\
\hline
\end{tabular}




\begin{tabular}{|c|c|}
\hline Capítulo & Texto \\
\hline & 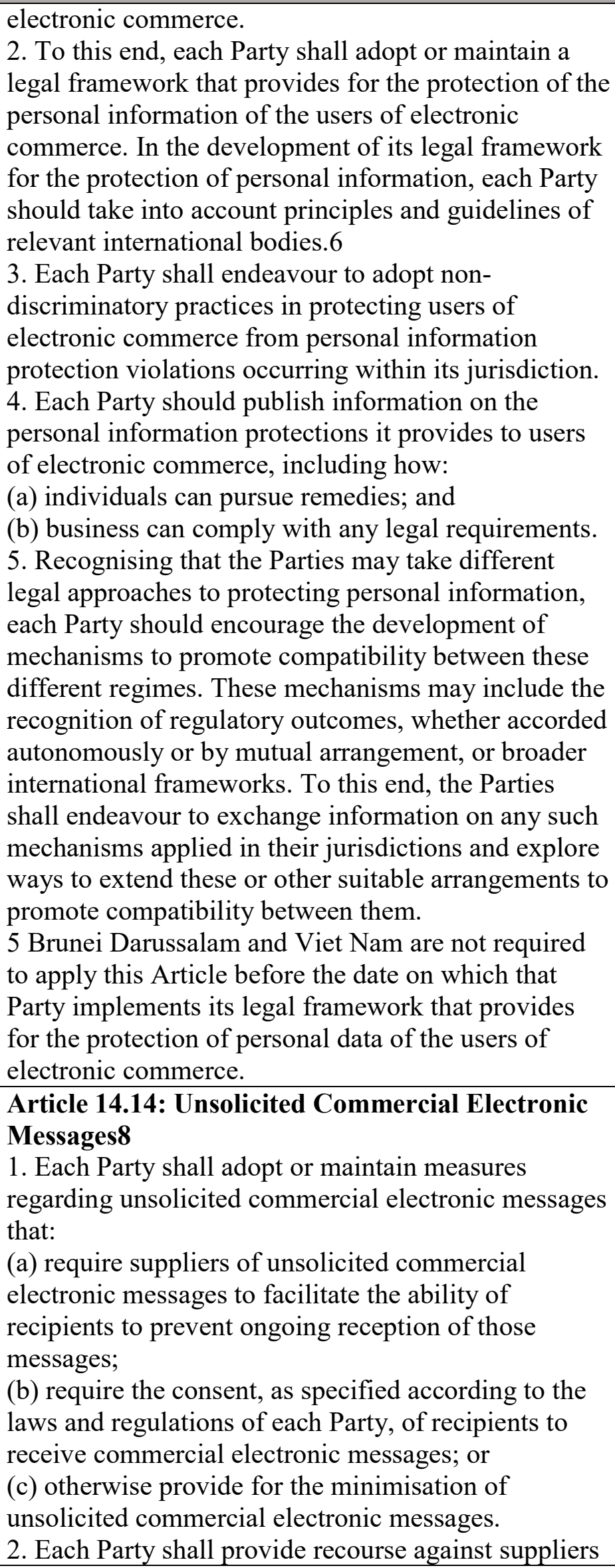 \\
\hline
\end{tabular}




\begin{tabular}{|c|c|}
\hline Capítulo & \begin{tabular}{|l} 
Texto \\
\end{tabular} \\
\hline & $\begin{array}{l}\text { of unsolicited commercial electronic messages that do } \\
\text { not comply with the measures adopted or maintained } \\
\text { pursuant to paragraph } 1 \text {. } \\
\text { 3. The Parties shall endeavour to cooperate in } \\
\text { appropriate cases of mutual concern regarding the } \\
\text { regulation of unsolicited commercial electronic } \\
\text { messages. } \\
8 \text { Brunei Darussalam is not required to apply this } \\
\text { Article before the date on which it implements its } \\
\text { legal framework regarding unsolicited commercial } \\
\text { electronic messages. }\end{array}$ \\
\hline & $\begin{array}{l}\text { Article 14.15: Cooperation } \\
\text { Recognising the global nature of electronic } \\
\text { commerce, the Parties shall endeavour to: } \\
\text { (a) work together to assist SMEs to overcome } \\
\text { obstacles to its use; } \\
\text { (b) exchange information and share experiences on } \\
\text { regulations, policies, enforcement and compliance } \\
\text { regarding electronic commerce, including: } \\
\text { (i) personal information protection; } \\
\text { (ii) online consumer protection including means for } \\
\text { consumer redress and building consumer confidence; } \\
\text { (iii) unsolicited commercial electronic messages; } \\
\text { (iv) security in electronic communications; } \\
\text { (v) authentication; and } \\
\text { (vi) e-government; } \\
\text { (c) exchange information and share views on } \\
\text { consumer access to products and services offered } \\
\text { online among the Parties; } \\
\text { (d) participate actively in regional and multilateral } \\
\text { fora to promote the development of electronic } \\
\text { commerce; and } \\
\text { (e) encourage development by the private sector of } \\
\text { methods of self-regulation that foster electronic } \\
\text { commerce, including codes of conduct, model } \\
\text { contracts, guidelines and enforcement mechanisms. }\end{array}$ \\
\hline & $\begin{array}{l}\text { Article 14.16: Cooperation on Cybersecurity } \\
\text { Matters } \\
\text { The Parties recognise the importance of: } \\
\text { (a) building the capabilities of their national entities } \\
\text { responsible for computer security incident response; } \\
\text { and } \\
\text { (b) using existing collaboration mechanisms to } \\
\text { cooperate to identify and mitigate malicious intrusions } \\
\text { or dissemination of malicious code that affect the } \\
\text { electronic networks of the Parties. }\end{array}$ \\
\hline
\end{tabular}

Fonte: Elaboração própria com informações do acordo TPP. 


\section{ANEXO V}

MAPEAMENTO DE DISPOSITIVOS DOS CAPÍTULOS DE SERVIÇOS DO TTIP DE COERÊNCIA REGULATÓRIA

\begin{tabular}{|c|c|}
\hline Capítulo & Texto \\
\hline & $\begin{array}{l}\text { Article 3-2 Market Access } \\
\text { In sectors or subsectors where market access } \\
\text { commitments are undertaken, neither Party shall } \\
\text { adopt or maintain with regards to market access } \\
\text { through the cross-border supply of services, either } \\
\text { on the basis of its entire territory or on the basis of a } \\
\text { territorial sub-division, measures that impose: } \\
\text { (a) limitations on the number of services suppliers } \\
\text { whether in the form of numerical quotas, } \\
\text { monopolies, exclusive service suppliers or the } \\
\text { requirements of an economic needs test; } \\
\text { (b) limitations on the total value of service } \\
\text { transactions or assets in the form of numerical } \\
\text { quotas or the requirement of an economic needs } \\
\text { test; } \\
\text { (c) limitations on the total number of service } \\
\text { operations or on the total quantity of service output } \\
\text { expressed in the terms of designated numerical units } \\
\text { in the form of quotas or the requirement of an } \\
\text { economic needs test. }\end{array}$ \\
\hline $\begin{array}{c}\text { CHAPTER III - CROSS } \\
\text { BORDER SUPPLY OF } \\
\text { SERVICES }\end{array}$ & $\begin{array}{l}\text { Article 3-3 National Treatment } \\
\text { 1. Each Party shall accord to services and service } \\
\text { suppliers of the other Party, in respect of all } \\
\text { measures affecting the cross-border supply of } \\
\text { services, treatment no less favourable than the } \\
\text { treatment it accords, in like situations, to its own } \\
\text { services and services suppliers. } \\
\text { 2. A Party may meet the requirement of paragraph } 1 \\
\text { by according to services and service suppliers of the } \\
\text { other Party either formally identical treatment or } \\
\text { formally different treatment to that it accords to its } \\
\text { own like services and service suppliers. } \\
\text { 3. Formally identical or formally different treatment } \\
\text { shall be considered to be less favourable if it } \\
\text { modifies the conditions of competition in favour of } \\
\text { services or service suppliers of the Party compared } \\
\text { to like services or service suppliers of the other } \\
\text { Party. } \\
\text { 4. Nothing in this article shall be construed to } \\
\text { require any Party to compensate for inherent } \\
\text { competitive disadvantages which result from the } \\
\text { foreign character of the relevant services or services } \\
\text { suppliers. }\end{array}$ \\
\hline
\end{tabular}




\begin{tabular}{|c|c|}
\hline Capítulo & Texto \\
\hline & $\begin{array}{l}13 \text { For greater certainty, Article } 2-3 \text { (National } \\
\text { Treatment) shall also be interpreted in accordance } \\
\text { with paragraphs } 2,3 \text { and } 4 \text { with respect to economic } \\
\text { activities performed through establishment. }\end{array}$ \\
\hline & $\begin{array}{l}\text { Article 3-4 Most Favoured Nation Treatment } \\
\text { 1. Each Party shall accord to shall grant to services } \\
\text { and service suppliers of the other Party, in respect } \\
\text { of all measures affecting the cross-border supply of } \\
\text { services, treatment no less favourable than the } \\
\text { treatment it accords, in like situations, to services } \\
\text { and service suppliers of any non-Party. } \\
\text { 2. Paragraph } 1 \text { shall not be construed to oblige a } \\
\text { Party to extend to services and service suppliers of } \\
\text { the other Party the benefit of any treatment resulting } \\
\text { from: } \\
\text { (a) [ reference to double taxation agreements in case } \\
\text { not covered by horizontal provisions in the } \\
\text { agreement] } \\
\text { (b) measures providing for the recognition of } \\
\text { qualifications, licences or prudential measures in } \\
\text { accordance with Article VII of the General } \\
\text { Agreement on Trade in Services or its Annex on } \\
\text { Financial Services. }\end{array}$ \\
\hline & $\begin{array}{l}\text { Article 3-5 Reservations and Exceptions } \\
\text { 1. Articles X (National Treatment), X (Most } \\
\text { Favoured Nation Treatment) do not apply to: } \\
\text { (a) any existing non-conforming measure that is } \\
\text { maintained by a Party at the level of: } \\
\text { (i) the European Union, as set out in its Annex I; } \\
\text { (ii) a national government, as set out by that Party } \\
\text { in its Annex I; } \\
\text { (iii) regional government, as set out by that Party in } \\
\text { its Annex I; or } \\
\text { (iv) a local government. } \\
\text { (b) the continuation or prompt renewal of any non- } \\
\text { conforming measure referred to in subparagraph } \\
\text { (a); or } \\
\text { (c) an amendment to any non-conforming measure } \\
\text { referred to in subparagraph (a) to the extent that the } \\
\text { amendment does not decrease the conformity of the } \\
\text { measure, as it existed immediately before the } \\
\text { amendment, with Articles X (National Treatment), } \\
\text { X ( Most Favoured Nation Treatment). } \\
\text { 2. Articles X (National Treatment), X (Most } \\
\text { Favoured Nation Treatment) do not apply to } \\
\text { measures that a Party adopts or maintains with } \\
\text { respect to sectors, subsectors or activities, as set out } \\
\text { in its Annex II. }\end{array}$ \\
\hline
\end{tabular}




\begin{tabular}{|c|c|}
\hline Capítulo & Texto \\
\hline & $\begin{array}{l}\text { 3. Article X (Market Access) does not apply to: } \\
\text { (a) any existing measure that is maintained by a } \\
\text { Party at the level of a local government; the } \\
\text { continuation or prompt renewal of such a non- } \\
\text { conforming measure; or an amendment to such a } \\
\text { measure to the extent that the amendment does not } \\
\text { decrease the conformity of the measure, as it existed } \\
\text { immediately before the amendment with Article X } \\
\text { (Market Access). } \\
\text { (b) any measure that a Party adopts or maintains } \\
\text { with respect to committed sectors or subsectors as } \\
\text { set out in its Annex III. }\end{array}$ \\
\hline $\begin{array}{c}\text { CHAPTER V - REGULATORY } \\
\text { FRAMEWORK } \\
\text { SECTION I - DOMESTIC } \\
\text { REGULATION }\end{array}$ & $\begin{array}{l}\text { Article 5-2 Conditions for licencing and } \\
\text { qualification } \\
\text { 1. Each Party shall ensure that measures relating to } \\
\text { licencing requirements and procedures, } \\
\text { qualification requirements and procedures are based } \\
\text { on criteria which preclude the competent authorities } \\
\text { from exercising their power of assessment in an } \\
\text { arbitrary manner. } \\
\text { 2. The criteria referred to in paragraph } 1 \text { shall be: } \\
\text { (a) proportionate to a legitimate public policy } \\
\text { objective; } \\
\text { (b) clear and unambiguous; } \\
\text { (c) objective; } \\
\text { (d) pre-established; } \\
\text { (e) made public in advance; } \\
\text { (f) transparent and accessible. } \\
\text { 3. An authorisation or a licence shall be granted as } \\
\text { soon as it is established, in the light of an } \\
\text { appropriate examination, that the conditions for } \\
\text { obtaining an authorisation or licence have been met. } \\
\text { 4. Each Party shall maintain or institute judicial, } \\
\text { arbitral or administrative tribunals or procedures } \\
\text { which provide, at the request of an affected investor } \\
\text { or service supplier, for a prompt review of, and } \\
\text { where justified, appropriate remedies for, } \\
\text { administrative decisions affecting the supply of a } \\
\text { service or the the pursuit of any other economic } \\
\text { activity. Where such procedures are not } \\
\text { independent of the agency entrusted with the } \\
\text { administrative decision concerned, each Party shall } \\
\text { ensure that the procedures in fact provide for an } \\
\text { objective and impartial review. } \\
\text { 5. Where the number of licences available for a } \\
\text { given activity is limited because of the scarcity of } \\
\text { available natural resources or technical capacity, } \\
\text { each Party shall apply a selection procedure to } \\
\text { potential candidates which provides full guarantees }\end{array}$ \\
\hline
\end{tabular}




\begin{tabular}{|c|c|}
\hline Capítulo & $\begin{array}{l}\text { Texto } \\
\end{array}$ \\
\hline & $\begin{array}{l}\text { of impartiality and transparency, including, in } \\
\text { particular, adequate publicity about the launch, } \\
\text { conduct and completion of the procedure. } \\
\text { 6. Subject to the provisions specified by this } \\
\text { Article, in establishing the rules for the selection } \\
\text { procedure, each Party may take into account } \\
\text { legitimate public policy objectives, including } \\
\text { considerations of health, safety, consumer } \\
\text { protection, the protection of the environment and } \\
\text { the preservation of cultural heritage. }\end{array}$ \\
\hline & $\begin{array}{l}\text { Article 5-3 Licencing and qualification } \\
\text { procedures } \\
\text { 1. Licencing and qualification procedures and } \\
\text { formalities shall be clear, made public in advance } \\
\text { and be such as to provide the applicants with a } \\
\text { guarantee that their application will be dealt with } \\
\text { objectively and impartially. } \\
\text { 2. Licencing and qualification procedures and } \\
\text { formalities shall be as simple as possible and shall } \\
\text { not unduly complicate or delay the provision of the } \\
\text { service or the pursuit of the economic activity. Any } \\
\text { authorization fees16 which the applicants may incur } \\
\text { from their application should be reasonable and } \\
\text { proportionate to the cost of the authorisation } \\
\text { procedures in question. } \\
\text { 3. Each party shall ensure that the procedures used } \\
\text { by, and the decisions of, the competent authority in } \\
\text { the licencing or authorisation process are impartial } \\
\text { with respect to all applicants. The competent } \\
\text { authority should reach its decision in an } \\
\text { independent manner and not be accountable to any } \\
\text { person supplying a service or pursuing an economic } \\
\text { activity for which the licence or authorisation is } \\
\text { required. } \\
\text { 4. Where specific time periods for applications } \\
\text { exist, an applicant shall be allowed a reasonable } \\
\text { period for the submission of an application. The } \\
\text { competent authority shall initiate the processing of } \\
\text { an application without undue delay. Where } \\
\text { possible, applications should be accepted in } \\
\text { electronic format under the same conditions of } \\
\text { authenticity as paper submissions. } \\
\text { 5. Each Party shall ensure that the processing of an } \\
\text { application, including reaching a final decision, is } \\
\text { completed within a reasonable timeframe from the } \\
\text { submission of a complete application. Each Party } \\
\text { shall endeavour to establish the normal timeframe } \\
\text { for processing of an application. }\end{array}$ \\
\hline
\end{tabular}




\begin{tabular}{|c|c|}
\hline Capítulo & Texto \\
\hline & $\begin{array}{l}\text { 6. The competent authority shall, within a } \\
\text { reasonable period of time after receipt of an } \\
\text { application which it considers incomplete, inform } \\
\text { the applicant, to the extent feasible identify the } \\
\text { additional information required to complete the } \\
\text { application, and provide the opportunity to correct } \\
\text { deficiencies. } \\
\text { 7. Authenticated copies should be accepted, where } \\
\text { possible, in place of original documents. } \\
\text { 8. If an application is rejected by the competent } \\
\text { authority, the applicant shall be informed in writing } \\
\text { and without undue delay. In principle, the applicant } \\
\text { shall, upon request, also be informed of the reasons } \\
\text { for rejection of the application and of the timeframe } \\
\text { for an appeal against the decision. An applicant } \\
\text { should be permitted, within reasonable time limits, } \\
\text { to resubmit an application. } \\
\text { 9. Each Party shall ensure that a licence or an } \\
\text { authorisation, once granted, enters into effect } \\
\text { without undue delay in accordance with the terms } \\
\text { and conditions specified therein. }\end{array}$ \\
\hline $\begin{array}{c}\text { CHAPTER V - REGULATORY } \\
\text { FRAMEWORK SECTION II - } \\
\text { PROVISIONS OF GENERAL } \\
\text { APPLICATION }\end{array}$ & $\begin{array}{l}\text { Article 5-4 Transparency and disclosure of } \\
\text { confidential information } \\
\text { 1. Each Party shall respond promptly to all requests } \\
\text { by the other Party for specific information on any of } \\
\text { its measures of general application or international } \\
\text { agreements which pertain to or affect this } \\
\text { Agreement. Each Party shall also establish one or } \\
\text { more enquiry points to provide specific information } \\
\text { to investors and services suppliers of the other } \\
\text { Party, upon request, on all such matters. The Parties } \\
\text { shall notify each other enquiry points within } 3 \\
\text { months after entry into force of this agreement. } \\
\text { Enquiry points need not be depositories of laws and } \\
\text { regulations. } \\
2 . \text { Nothing in this Agreement shall require any Party } \\
\text { to provide confidential information, the disclosure } \\
\text { of which would impede law enforcement, or } \\
\text { otherwise be contrary to the public interest, or } \\
\text { which would prejudice legitimate commercial } \\
\text { interests of particular enterprises, public or private. }\end{array}$ \\
\hline
\end{tabular}




\begin{tabular}{|c|c|}
\hline Capítulo & Texto \\
\hline & $\begin{array}{l}\text { Article 5-6 Objectives and Scope } \\
\text { 1. This Section establishes the framework to } \\
\text { facilitate a fair, transparent and consistent regime } \\
\text { for the mutual recognition of professional } \\
\text { qualifications by the Parties and sets out the general } \\
\text { conditions for the negotiation of MRAs. } \\
\text { 2. This Section applies to professions which are } \\
\text { regulated in each Party, including in all or some } \\
\text { Member States of the European Union and as } \\
\text { regards the United States in all or some states, the } \\
\text { District of Columbia, Puerto Rico. } \\
\text { 3. A Party shall not accord recognition in a manner } \\
\text { that would constitute a means of discrimination in } \\
\text { the application of its criteria for the authorisation, } \\
\text { licensing or certification of a service supplier, or } \\
\text { that would constitute a disguised restriction on trade } \\
\text { in services. } \\
4 . \text { A MRA adopted pursuant to this Section shall } \\
\text { apply throughout the entire territory of the EU and } \\
\text { the US. }\end{array}$ \\
\hline $\begin{array}{l}\text { CHAPTER V - REGULATORY } \\
\text { FRAMEWORK SECTION III - } \\
\text { MUTUAL RECOGNITION OF } \\
\text { PROFESSIONAL } \\
\text { QUALIFICATIONS }\end{array}$ & $\begin{array}{l}\text { Article 5-7 Negotiation of a MRA } \\
\text { 1. The Parties shall encourage its Relevant } \\
\text { Authorities or professional bodies, as appropriate, } \\
\text { to develop and provide to the Committee on Mutual } \\
\text { Recognition of Professional Qualifications ("MRA } \\
\text { Committee") joint recommendations on proposed } \\
\text { MRAs. } \\
\text { 2. A recommendation shall provide an assessment } \\
\text { as to the compatibility of the respective licensing or } \\
\text { qualification regimes and the intended approach for } \\
\text { the negotiation of a MRA. In addition, it shall } \\
\text { provide an assessment of the potential economic } \\
\text { value of a MRA, on the basis of criteria such as the } \\
\text { existing level of market openness, industry needs, } \\
\text { and business opportunities, for example, the number } \\
\text { of professionals likely to benefit from the MRA, the } \\
\text { existence of other MRAs in the sector, and expected } \\
\text { gains in terms of economic and business } \\
\text { development. } \\
\text { 3. In light of each Party's consultations with its } \\
\text { respective Relevant Authorities, the MRA } \\
\text { Committee shall, within a reasonable period of } \\
\text { time, review the recommendation with a view to } \\
\text { ensuring its consistency with the requirements of } \\
\text { this Section. If these requirements are satisfied, the } \\
\text { MRA Committee shall establish the necessary steps } \\
\text { to negotiate a draft MRA. } \\
\text { 4. The negotiating entities shall thereafter pursue } \\
\text { the negotiation, involving their respective Relevant }\end{array}$ \\
\hline
\end{tabular}




\begin{tabular}{|c|c|}
\hline Capítulo & Texto \\
\hline & $\begin{array}{l}\text { Authorities, as needed, and submit a draft MRA text } \\
\text { to the MRA Committee. } \\
5 \text {. If in the view of the MRA Committee the MRA } \\
\text { is consistent with the Agreement, the MRA } \\
\text { Committee shall adopt the MRA by means of a } \\
\text { decision. }\end{array}$ \\
\hline & $\begin{array}{l}\text { Article 5-8 Recognition } \\
\text { 1. The recognition of professional qualifications } \\
\text { provided by a MRA shall allow the beneficiary to } \\
\text { take up and pursue professional activities in the host } \\
\text { jurisdiction, in accordance with the terms and } \\
\text { conditions specified in the MRA. } \\
\text { 2. If the professional qualifications of a service } \\
\text { supplier in a Party are recognised by the other Party } \\
\text { pursuant to a MRA, a Relevant Authority of the } \\
\text { host jurisdiction shall accord to this service supplier } \\
\text { treatment no less favourable than that accorded in } \\
\text { like situations to a like service supplier whose } \\
\text { professional qualifications have been certified or } \\
\text { attested in the host Party's jurisdiction. } \\
\text { 3. Recognition under a MRA cannot be conditioned } \\
\text { upon: } \\
\text { (a) a service supplier meeting a citizenship or any } \\
\text { form of residency requirement; or } \\
\text { (b) a service supplier's education, experience or } \\
\text { training having been acquired in the host Party's } \\
\text { jurisdiction. }\end{array}$ \\
\hline & $\begin{array}{l}\text { Article 5-9 Committee on Mutual Recognition of } \\
\text { Professional Qualifications } \\
\text { 1. The Committee on Mutual Recognition of } \\
\text { Professional Qualifications (MRA Committee), } \\
\text { established under Article XX, and responsible for } \\
\text { the implementation of Article X and X shall: } \\
\text { (a) be composed and co-chaired by the United } \\
\text { States and the European Union; } \\
\text { (b) comprise of representatives of each Party which } \\
\text { must be different from the Relevant Authorities or } \\
\text { professional bodies referred to in Article X.3.1. The } \\
\text { list of those representatives shall be communicated } \\
\text { through an exchange of letters; } \\
\text { (c) meet within one year after this Agreement } \\
\text { enters into force, and thereafter as necessary or as } \\
\text { decided; } \\
\text { (d) determine its own rules of procedure; } \\
\text { (e) facilitate the exchange of information regarding } \\
\text { laws, regulations, policies and practices concerning } \\
\text { standards or criteria for the authorisation, licensing } \\
\text { or certification of regulated professions; } \\
\text { (f) make publicly available information regarding }\end{array}$ \\
\hline
\end{tabular}




\begin{tabular}{|l|l|}
\hline \multicolumn{1}{|c|}{ Capítulo } & \multicolumn{1}{|c|}{ Texto } \\
\hline & the negotiation and implementation of MRAs; \\
(g) report to the Joint Committee on the progress of \\
the negotiation and implementation of MRAs; \\
(h) as appropriate, provide information and \\
complement the guidelines set out in the Annex X- \\
A to this Section; and (i) have the possibility to take \\
decisions in accordance with Art X.
\end{tabular}




\begin{tabular}{|c|c|}
\hline Capítulo & Texto \\
\hline & 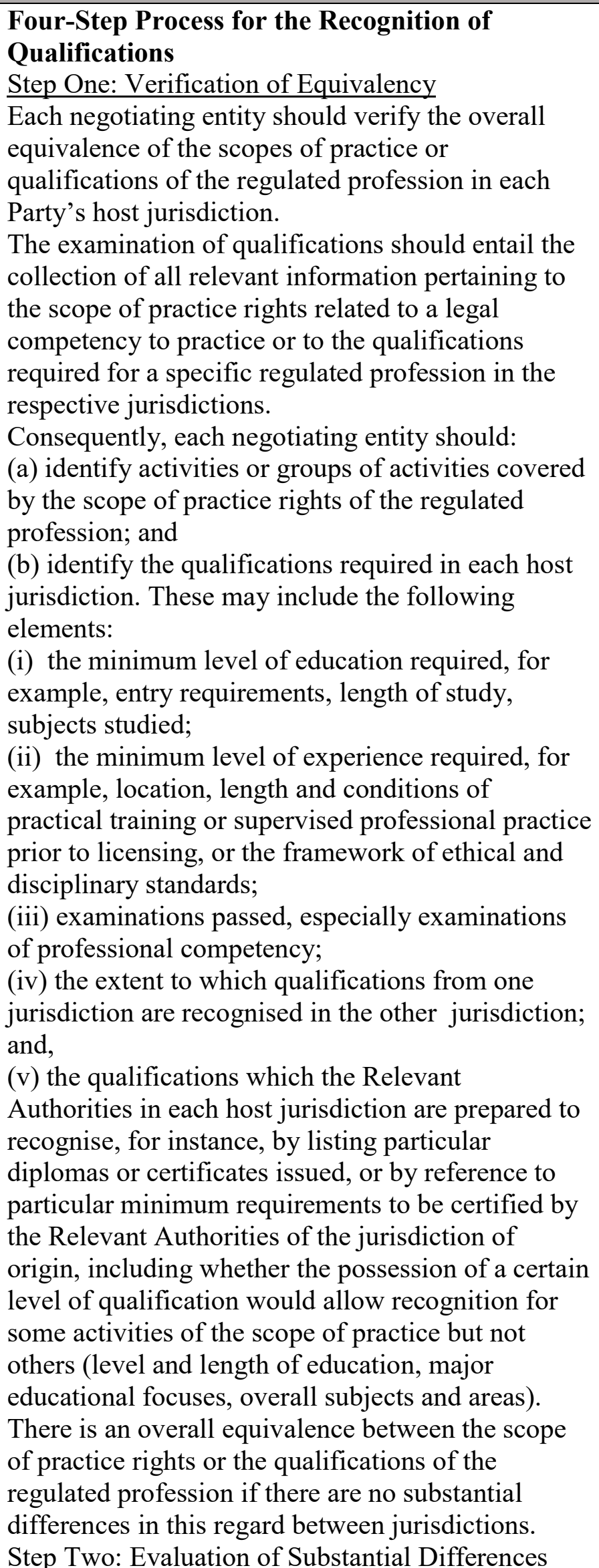 \\
\hline
\end{tabular}




\begin{tabular}{|c|c|}
\hline Capítulo & $\begin{array}{l}\text { Texto } \\
\end{array}$ \\
\hline & $\begin{array}{l}\text { There exists a substantial difference in the scope of } \\
\text { qualifications required to exercise a regulated } \\
\text { profession, in cases of: } \\
\text { (a) important differences in the essential } \\
\text { knowledge; or } \\
\text { (b) significant differences in the duration or content } \\
\text { of the training between the host jurisdictions. } \\
\text { There exists a substantial difference in the scope of } \\
\text { practice if: } \\
\text { (a) one or more professional activities do not form } \\
\text { part of the corresponding profession in the } \\
\text { jurisdiction of origin; } \\
\text { (b) these activities are subject to specific training in } \\
\text { the host jurisdiction; and, } \\
\text { (c) the training for these activities in the host } \\
\text { jurisdiction covers substantially different matters } \\
\text { from those covered by the applicant's qualification. } \\
\text { Step Three: Compensatory Measures } \\
\text { If each negotiating entity determines that there is a } \\
\text { substantial difference in the scope of practice rights } \\
\text { or of formal qualifications between the host } \\
\text { jurisdictions, they may determine compensatory } \\
\text { measures to bridge the gap. } \\
\text { Compensatory measures should be proportionate to } \\
\text { the substantial difference which they seek to } \\
\text { address. Each negotiating entity should evaluate any } \\
\text { practical professional experience obtained in the } \\
\text { jurisdiction of origin to see whether this experience } \\
\text { is sufficient to remedy, in whole or in part, the } \\
\text { substantial difference in the scope of practice rights } \\
\text { or formal qualifications between the host } \\
\text { jurisdictions, prior to determining a compensatory } \\
\text { measure. A compensatory measure may also take } \\
\text { the form of, among other things, an adaptation } \\
\text { period or, if required, an aptitude test. } \\
\text { measure, including the use of any adaptation period } \\
\text { Step Four: Identification of the Conditions for } \\
\text { Recognition } \\
\text { (b) the extent to which professional experience may } \\
\text { Once the assessment of the overall equivalency of } \\
\text { the scopes of practice rights or qualifications of the } \\
\text { regulated profession is completed, each negotiating } \\
\text { entity should specify in the MRA: } \\
\text { (a) the legal competency required to practice the } \\
\text { (egulated profession; }\end{array}$ \\
\hline
\end{tabular}




\begin{tabular}{|c|c|}
\hline Capítulo & Texto \\
\hline & $\begin{array}{l}\text { or aptitude test, to the extent needed. } \\
\text { 5. Mechanisms for Implementation } \\
\text { The MRA should state: } \\
\text { (a) the rules and procedures to be used to monitor } \\
\text { and enforce the provisions of the agreement; } \\
\text { (b) the mechanisms for dialogue and administrative } \\
\text { co-operation between the parties to the MRA; and } \\
\text { (c) the means for individual applicants to address } \\
\text { any matters arising from the interpretation or } \\
\text { implementation of the MRA. } \\
\text { As a guide to the treatment of individual applicants, } \\
\text { the MRA should include details on: } \\
\text { (a) the point of contact for information on all issues } \\
\text { relevant to the application, for example, the name } \\
\text { and address of the Relevant Authorities, licensing } \\
\text { formalities, information on additional requirements } \\
\text { which need to be met in the host jurisdiction; } \\
\text { (b) the duration of the procedures for the processing } \\
\text { of applications by the Relevant Authorities of the } \\
\text { host jurisdiction; } \\
\text { (c) the documentation required of applicants and the } \\
\text { form in which it should be presented ; } \\
\text { (d) acceptance of documents and certificates issued } \\
\text { in the host jurisdiction in relation to qualifications } \\
\text { and licensing; } \\
\text { (e) the procedures of appeal to or review by the } \\
\text { Relevant Authorities. } \\
\text { The MRA should also include the following } \\
\text { commitments by the Relevant Authorities: } \\
\text { (a) requests about the measures will be promptly } \\
\text { lealt with; } \\
\text { licence is obtained following the determination of } \\
\text { eligibility, and what a licence entails, for example, a } \\
\text { licence and its contents, membership of a } \\
\text { necessary; } \\
\text { (c) exams or tests will be arranged with reasonable } \\
\text { frequency; } \\
\text { (d) fees for applicants seeking to take advantage of } \\
\text { the terms of the MRA will be commensurate with } \\
\text { the costs incurred by the host jurisdiction; and } \\
\text { (e) information will be supplied on any assistance } \\
\text { programmes in the host jurisdiction for practical } \\
\text { training, and any commitments of the host } \\
\text { jurisdiction in that context. } \\
\text { 6. Licensing and Other Provisions in the Host } \\
\text { lotion }\end{array}$ \\
\hline
\end{tabular}




\begin{tabular}{|c|c|}
\hline Capítulo & Texto \\
\hline & $\begin{array}{l}\text { professional body, use of professional or academic } \\
\text { titles. Any licensing requirements other than } \\
\text { qualifications should be explained and should } \\
\text { include requirements relating to: } \\
\text { (a) having an office address, maintaining an } \\
\text { establishment or being a resident; } \\
\text { (b) language skills; } \\
\text { (c) proof of good character; } \\
\text { (d) professional indemnity insurance; } \\
\text { (e) compliance with host jurisdiction's requirements } \\
\text { for use of trade or firm names; and } \\
\text { (f) compliance with host jurisdiction ethicsfor } \\
\text { example, independence and good conduct; } \\
\text { To ensure transparency, the MRA could include the } \\
\text { following details for each host jurisdiction: } \\
\text { (a) the relevant law to be applied, for example, } \\
\text { regarding disciplinary action, financial } \\
\text { responsibility, liability; } \\
\text { (b) the principles of discipline and enforcement of } \\
\text { professional standards, including disciplinary } \\
\text { jurisdiction and any consequential effects on } \\
\text { practicing professional activities; } \\
\text { (c) the means for the ongoing verification of } \\
\text { competence; and } \\
\text { (d) the criteria for, and procedures relating to, } \\
\text { revocation of the registration. } \\
\text { 7. Revision of the MRA } \\
\text { If the MRA includes terms under which it can be } \\
\text { reviewed or revoked, the details should be clearly } \\
\text { stated. } \\
\text { 8. Transparency } \\
\text { The Parties should: } \\
\text { (a) make publicly available the text of MRAs which } \\
\text { have been concluded; and, } \\
\text { (b) notify each other of any modifications to } \\
\text { qualifications that may affect the application or } \\
\text { implementation of a MRA. If possible, a Party } \\
\text { should be given an opportunity to comment on the } \\
\text { modifications of the other Party. }\end{array}$ \\
\hline $\begin{array}{c}\text { Sub-section } 2-\text { Regulatory } \\
\text { cooperation in financial services }\end{array}$ & $\begin{array}{l}\text { Article } 5 \text { - } 38 \text { Regulatory cooperation } \\
\text { 1. The Parties recognize that prudential measures } \\
\text { strengthen domestic financial systems; encourage } \\
\text { sound, efficient and robust institutions, markets, and } \\
\text { infrastructure; and promote international financial } \\
\text { stability by facilitating betterinformed lending and } \\
\text { investment decisions, improving market integrity, } \\
\text { and reducing the risks of financial distress and } \\
\text { contagion. } \\
\text { 2. The Parties undertake to use their best }\end{array}$ \\
\hline
\end{tabular}




\begin{tabular}{|c|c|}
\hline Capítulo & Texto \\
\hline & $\begin{array}{l}\text { endeavours to achieve mutual compatibility of their } \\
\text { respective regulatory and supervisory frameworks } \\
\text { for financial services in a way that supports the } \\
\text { objectives mentioned in paragraph 1. Furthermore, } \\
\text { the general objectives and principles of the Chapter } \\
\text { [Regulatory Cooperation] apply to regulatory } \\
\text { cooperation on financial services. } \\
\text { 3. The Parties agree to consult each other at the } \\
\text { earliest stage of the regulatory process. } \\
\text { 4. The Parties agree, wherever possible, defer to } \\
\text { the rules of the other Party if they achieve } \\
\text { comparable outcomes, for the purpose of assessing } \\
\text { compliance with domestic regulations. } \\
\text { 5. The Parties shall conduct their cooperation in } \\
\text { respect of financial services through a Joint EU/US } \\
\text { Financial Regulatory Forum ("the Forum"), which } \\
\text { is hereby established. The Forum shall be composed } \\
\text { of representatives of regulators, supervisors and } \\
\text { competent authorities responsible for financial } \\
\text { regulation. In the area of financial services it shall } \\
\text { carry out the functions of the Regulatory } \\
\text { Cooperation Council established in Article } 14 \text { par. } 1 \\
\text { of the Chapter [on Regulatory Cooperation]. } \\
6 \text {. The detailed arrangements of regulatory } \\
\text { cooperation shall be set out in a [Memorandum of } \\
\text { Understanding on Regulatory Cooperation in } \\
\text { Financial Services20] } \\
\text { NB: The relationship between the provisions of } \\
\text { Chapter [] - Regulatory cooperation and the } \\
\text { provisions for regulatory cooperation in financial } \\
\text { services will be kept under review, as both sets of } \\
\text { provisions are taking shape. The provisions for } \\
\text { regulatory cooperation in financial services are built } \\
\text { on the premise that they will apply to regulatory } \\
\text { acts adopted by the EU and US Federal authorities, } \\
\text { as well as to acts adopted by US States and EU } \\
\text { Member States. }\end{array}$ \\
\hline $\begin{array}{c}\text { CHAPTER VI - ELECTRONIC } \\
\text { COMMERCE }\end{array}$ & $\begin{array}{l}\text { Article 6-8 Cooperation on regulatory issues in e- } \\
\text { commerce24 } \\
\text { 1. The parties shall maintain a dialogue on } \\
\text { regulatory issues raised by electronic commerce, } \\
\text { which shall inter alia address the following issues: } \\
\text { - the recognition and facilitation of interoperable } \\
\text { cross-border electronic trust and authentication } \\
\text { services; } \\
\text { - the treatment of direct marketing } \\
\text { communications; } \\
\text { - the protection of consumers in the ambit of } \\
\text { electronic commerce; and }\end{array}$ \\
\hline
\end{tabular}




\begin{tabular}{|l|l|}
\hline Capítulo & \multicolumn{1}{|c|}{ Texto } \\
\hline & $\begin{array}{l}|c| \\
\text { electronic commerce. } \\
\text { 2. Such cooperation shall focus on exchange of } \\
\text { information on the Parties' respective legislation on } \\
\text { these issues as well as on the implementation of } \\
\text { such legislation. } \\
\text { 24 The relation between this chapter and the chapter } \\
\text { on regulatory cooperation will be further discussed. }\end{array}$ \\
\hline
\end{tabular}

Fonte: Elaboração própria com informações do acordo TTIP. 